\title{
MERCADOS INFORMALES Y CONTROL VERTICAL: COMERCIALIZACIÓN DE PRODUCCIÓN PERECIBLE*
}

\author{
Julio Peña-Torres, R. Javier Bustos y Claudio Pérez
}

Este trabajo desarrolla un estudio de caso de cambios institucionales ocurridos desde fines de los años 90 en la pesquería artesanal de Merluza Austral en Chile. Esta pesquería, que exporta la totalidad de su producción en formato "fresco", constituye un caso pionero en Chile de acción colectiva exitosa y autogobierno en comunidades de pesca artesanal que explotan recursos marinos móviles. Esta pesquería sufrió una crisis de productividad desde fines de los años 80, durante casi una década. En reacción a esto, organizaciones de pescadores iniciaron conversaciones con la autoridad sectorial para intro-

Julio Peña-Torres. Profesor Adjunto del Departamento de Economía y Administración, ILADES-Universidad Alberto Hurtado. Email: jpena@uahurtado.cl

R. JAVIER Bustos S. Master of Arts in Economics, ILADES/Georgetown University.Email: rbustos@uahurtado.cl

Claudio Pérez. Estudiante de Sociología, Universidad Alberto Hurtado. Email: capbarros@uahurtado.cl

* Deseamos agradecer los valiosos comentarios e informaciones brindadas por los siguientes miembros de la Subsecretaría de Pesca: Andrés González, Edith Saa, Vilma Correa, Alejandro Gertosio, Ricardo Radebach y Marcelo García. Igualmente agradecemos la colaboración de Renato Céspedes (IFOP), Ricardo Badilla (Consultora Pupelde) y Francisco Ojeda (Consultora Huelén, ex gerente Consultora Pupelde). También agradecemos la importante colaboración de otros entrevistados que han preferido mantener su anonimato. Por último, agradecemos los útiles comentarios y sugerencias de evaluadores anónimos de este trabajo, y el apoyo financiero del proyecto Fondecyt $\mathrm{N}^{\circ} 1020765$.

Estudios Públicos, 101 (verano 2006). 
ducir nuevas reglas de regulación pesquera. Luego de un proceso de evolución gradual, actualmente opera un sistema de facto de cuotas individuales de pesca, con importante participación de organizaciones de pescadores en el control y manejo de la pesquería. Este trabajo analiza aspectos de organización industrial que han condicionado las soluciones de intercambio imperantes en el sector. Destacan la persistencia de significativa concentración industrial en la comercialización mayorista de la producción exportada, como también el uso de diferentes mecanismos de control vertical en el intercambio entre comercializadores mayoristas, exportadores, procesadores y agentes intermediarios que contratan la pesca con los pescadores. Aspectos contractuales que se analizan incluyen: el uso de transacciones informales, intercambios multidimensionales con una misma contraparte comercial, especificidad temporal en el valor del intercambio fruto de la perecibilidad del producto, el uso de diferentes mecanismos de control vertical y la influencia de una creciente concentración industrial a medida que se avanza en la cadena de comercialización mayorista hacia los mercados finales de exportación.

\section{Introducción}

$\mathrm{E}$ ste trabajo desarrolla un estudio de caso de un sector productivo del cual se ha escrito muy poco en Chile. El caso se refiere a la pesquería artesanal de merluza austral (Merluccius australis), una especie con elevado valor de exportación y que es capturada entre la X y XII Región. La evolución institucional de esta pesquería en la última década representa un proceso pionero y virtualmente único en Chile, y sin duda de excepción a nivel mundial, considerando sectores productivos que explotan recursos naturales móviles bajo propiedad común.

Un conjunto de comunidades de pescadores artesanales que operan en esta pesquería han logrado éxito organizativo para controlar el esfuerzo $\checkmark$ extractivo de las distintas flotas artesanales en operación. Y esto, a pesar ¿ que el sector extractivo presenta importante atomización y que el recurso $\because$ pesquero está de jure bajo propiedad común. Las innovaciones institucionales introducidas han implicado sistemas de gestión y control de la pesca O con importantes espacios de autogobierno por parte de comunidades de - pescadores. Voluntariamente organizaciones de pescadores han optado por implementar sistemas de gestión que involucran un uso de facto de cuotas 3 individuales de pesca. 
En la legislación chilena la pesca artesanal se define según características tecnológicas de la embarcación (su eslora y otras). Sin embargo, desde un punto de vista socioeconómico existe un conjunto de otros aspectos del sector que son de especial interés. Por un lado, el esfuerzo extractivo suele involucrar un número significativo de pescadores que operan en pequeñas escalas de extracción. Por otro, la producción del sector involucra un elevado grado de perecibilidad junto con calidades heterogéneas de producto (tamaños de los peces, su grado de frescura). La perecibilidad genera especificidad temporal en el valor de la producción, lo que implica riesgo de comportamiento oportunista de la contraparte comercial (e. g., Pirrong, 1993). Mientras que calidades heterogéneas generan costos de monitoreo y, asociado a éstos, problemas de selección adversa en la oferta de la producción (e. g., Kenney y Klein, 1983).

Adicionalmente, la pesca artesanal involucra grados importantes de informalidad en sus intercambios comerciales. Influye que los pescadores no dispongan de registros formales de historia laboral o de capacitación, ni tampoco activos colaterizables que les permitan acceder al crédito formal. Como consecuencia, y para hacer viable el intercambio económico, en transacciones con pescadores no es extraño observar la entrega de múltiples servicios y/o productos por parte de una misma contraparte comercial. Esto reduce los costos de transar y ayuda a resolver diversos problemas de agencia, debido a los incentivos complementarios de cumplimiento contractual que se generan a partir de relaciones comerciales multidimensionales, fenómeno descrito en la literatura económica como contratos con interlinkages (Braverman y Stiglitz ,1982; Bardhan, 1989; Basu, 1997) ${ }^{1}$.

La pesca artesanal de merluza austral comparte cada una de las características transaccionales aquí descritas. Su total especialización en producción exportable de merluza en 'fresco' determina grados significativos de especificidad temporal en el valor del intercambio, como también calidades heterogéneas relacionadas con la textura y frescura del producto en fresco.

Este estudio de caso motiva el análisis relacionado con tres temas generales de discusión. En primer lugar, aspectos que afectan a la organización de acción colectiva exitosa en sectores productivos informales, atomizados y parcialmente relacionados con contextos de pobreza rural. En la pesquería por analizar, una acción colectiva exitosa por parte de organiza-

\footnotetext{
${ }^{1}$ Este tipo de solución contractual ha sido analizado sobre todo para transacciones en sectores de economía rural, involucrando diferentes productos agrícolas. Por ejemplo, Little y Watts (1994) ofrecen una interesante colección de estudios de casos sobre el uso de este tipo de contratos en diferentes agroindustrias en el África subsahariana.
} 
ciones de pescadores ha contribuido a integrar a productores informales y de pequeña escala en una moderna industria de exportación. Al respecto, proveemos análisis del proceso de cambio institucional en la base del éxito de coordinación del esfuerzo extractivo, examinando los factores que han contribuido a este logro.

En segundo lugar, analizamos estrategias de intercambio y mecanismos contractuales que han permitido viabilizar el intercambio comercial en este tipo de sector productivo. Destaca la persistencia de una significativa concentración industrial en la fase de comercialización mayorista de la producción. También resalta el uso de instrumentos contractuales de control vertical que van más allá de meras transacciones anónimas en mercados de tipo spot. Sobre lo último, analizamos distintas estrategias de control vertical (acuerdos de aprovisionamiento exclusivo, financiamiento ex ante, integración vertical y otras) que permiten coordinar las decisiones de producción e intercambio entre agentes extractivos, plantas procesadoras, exportadores y firmas importadoras y de comercialización mayorista en el principal mercado de destino final de esta producción (España).

En tercer lugar, este estudio de caso también plantea hipótesis sobre las razones para utilizar arreglos contractuales informales, sobre todo en los intercambios relacionados con la fase extractiva. Como suele ocurrir al analizar el funcionamiento de mercados informales (e. g., Hernando de Soto, 1987; Thomas, 1999), parte de los argumentos presentados se relacionan con arreglos contractuales eficientes que buscan minimizar los costos de transar; también se sugiere la posibilidad de otras motivaciones tendientes a evitar costos asociados al intercambio vía mercados formales y legales.

La estructura del trabajo es como sigue. A continuación se revisa literatura relacionada con aspectos socioeconómicos relevantes para el caso bajo estudio. La sección 3 describe la evolución histórica de la pesquería, mientras que la sección 4 analiza el proceso de cambio institucional que ha permitido aliviar el problema de sobreexplotación del recurso pesquero. Las secciones 5 y 7 describen aspectos de concentración industrial en las fases de comercialización mayorista y de exportación de la producción en fresco de esta pesquería. La sección 6 analiza el uso de diferentes instrumentos de control vertical en las fases iniciales de intermediación de la producción y en su comercialización mayorista hacia el mercado predominante de exportación (España). La secciones 8 y 9 analizan patrones de interacción comercial entre agentes exportadores hacia el mercado español y el importador dominante, como también instancias de entrada y amenaza a la participación de mercado del agente comercializador-importador dominante. Finalmente, la sección 10 presenta conclusiones. 


\section{Literatura relacionada}

a) Acción colectiva y recursos naturales bajo propiedad común

Una variante de la literatura respecto de recursos bajo propiedad común se refiere a la posibilidad de organizar una acción colectiva para evitar la sobreexplotación. Este argumento suele adquirir mayor relevancia para comunidades de usuarios locales, i. e. con vínculos cercanos de interacción productiva y social, condicionado por variables tales como el número de usuarios, aspectos de heterogeneidad entre ellos, el grado de dependencia económica con relación al recurso bajo propiedad común y la repetición en el tiempo de interacciones entre miembros del grupo.

Referencias clásicas se encuentran en Berkes (1989), Ostrom (1990), Seabright (1993), Ostrom et al. (1994) y Sethi y Somanathan (1996). Una proporción importante de la evidencia de acción colectiva exitosa al administrar 'comunes locales' se refiere a recursos no móviles, e. g., terrenos de pastura y bosques.

En el caso de Chile y respecto de recursos marinos cuasi fijos, Castilla (1994), Gonzalez (1996), Agüero (2001) y Palma y Chávez (2004) ofrecen análisis de experiencias de manejo comunitario de recursos bentónicos (fijos en distintos grados al fondo marino), bajo el concepto legal de "Áreas de Manejo y Explotación de Recursos Bentónicos”2. Para similar tipo de recursos marinos, Ruddle (1988) y Orensanz (2001) proveen evidencia de sistemas de manejo comunitario en Japón y diversas islas de Oceanía y de la cuenca del Pacífico.

En relación con las pesquerías costeras que explotan recursos locales con mayor movilidad, hay evidencia de que las acciones colectivas exitosas tienden a ser de escasa ocurrencia. Ostrom (1990) cita los casos de algunas pesquerías locales en Sri Lanka, Turquía y Estados Unidos (e.g., McCay, 1980, y Acheson, 1988), y que en cada caso reflejan distintos grados de éxito en la organización de acción colectiva. Por otro lado, Cordell y บ McKean (1992) analizan la asignación de derechos informales de tenencia sobre áreas marinas con diversos recursos pesqueros, en sectores de manglares en Bahía, Brasil.

${ }^{2}$ Por ejemplo, para el manejo y explotación de locos, ostiones y machas. Al respecto, la ley chilena permite que se establezcan áreas de manejo para uso exclusivo de comunidades de pescadores artesanales. Para que una comunidad de pescadores pueda obtener un área de manejo, primero debe constituir una organización legal (e. g., sindicato) y luego presentar un plan de manejo y explotación que debe ser aprobado por la autoridad sectorial. 
b) Estrategias de intercambio y soluciones contractuales en industrias pesqueras

En general hay muy escasa literatura empírica sobre soluciones contractuales, e incluso sobre otros aspectos más generales de organización industrial, en industrias pesqueras. Si bien existe literatura que analiza mecanismos de pago usados para retribuir el esfuerzo productivo de tripulaciones de barcos pesqueros (Sutinen, 1979; Platteau y Nugent, 1992; Anderson, 1994), es mucho más escasa la evidencia publicada sobre arreglos contractuales y estructuras de mercado en otras fases del negocio pesquero. La carencia de información se exacerba para el caso de fases de comercialización de producción pesquera. Este trabajo constituye un aporte en esta área.

Respecto de relaciones contractuales entre fases de procesamiento y de extracción, Gallick (1984) y Koss (1989) analizan otras industrias pesqueras que utilizan soluciones contractuales y mecanismos de control vertical que presentan similitud con los descritos en el presente trabajo. Gallick (1984) analiza acuerdos de aprovisionamiento exclusivo e integración vertical entre empresas procesadoras y pescadores en la industria conservera del atún en Estados Unidos. Por su parte, Koss (1989) estudia soluciones contractuales entre procesadores y botes pesqueros, dada la presencia de inversiones de uso específico. Para eso analiza las pesquerías en British Columbia de salmón salvaje y de otras especies de carne blanca procesadas para consumo humano, incluyendo black cod o sablefish (sustituto comercial del bacalao de profundidad chileno) y halibut.

c) Concentración industrial en el procesamiento y comercialización de productos alimenticios

Diversos estudios describen la presencia de significativa concentración industrial en fases de procesamiento de diferentes industrias productoras de alimentos (Scott, 1984; Howard et al., 1996; Little y Watt, 1994). En una proporción importante de estos casos, la concentración industrial suele estar asociada al poder cuasi monopsónico sobre la compra de la producción primaria.

Además de compradores cuasi monopsónicos, es frecuente observar el uso de distintos mecanismos de control vertical, coordinando los flujos de producción en fases extractivas, de procesamiento y comercialización. La 
literatura económica denomina a estos esquemas como 'cadenas de producción’ o 'producción bajo contrato'. Una de las razones fundamentales para usar este tipo de esquemas es la reducción de los costos de transar. Los ahorros en costos de transacción suelen estar asociados con aspectos de perecibilidad y valor específico de la producción, monitoreo de calidades heterogéneas de producto, intercambio eficiente de riesgos financieros y productivos, como también de mercados segmentados de crédito en donde se monitorea al agente deudor mediante instancias adicionales de intercambio entre las partes.

Un conjunto de estudios ha analizado 'producción bajo contrato' en sectores agroindustriales (e. g., Little y Watt, 1994; Glover y Kusterer, 1990; Korovkin, 1992). También existe evidencia sobre el uso de 'cadenas de producción' en industrias productoras de carnes de vacuno, cerdo y aves (e. g., Barkema et al., 2001; Martínez, 1999 y 2002).

En el caso de industrias pesqueras, la literatura económica ha analizado efectos asignativos asociados a sectores cuasi monopsónicos de procesamiento, que compran pesca a sectores extractores atomizados y que operan sobre stocks pesqueros bajo propiedad común. Esta literatura ha analizado decisiones de integración vertical, aunque focalizada exclusivamente en decisiones asociadas al poder de precios del agente procesador (e. g., Crutchfield y Pontecorvo, 1969; Clark y Munro, 1980; Munro, 1982; Schworm, 1983; Stollery, 1987). Excluye por lo tanto análisis de otros instrumentos de control vertical. El análisis que el presente trabajo desarrolla sobre este último aspecto constituye un aporte en este sentido.

Adicionalmente, nuestro estudio de caso plantea la existencia de importante concentración industrial en la comercialización mayorista de la producción pesquera. Aunque existe escasa evidencia publicada al respecto, fuentes especializadas sugieren que la concentración industrial en la comercialización mayorista de productos pesqueros no es un fenómeno infrecuente (Doeringer y Terkla, 1995; Arnason, 1995; Anderson, 2003). Por ejemplo, Geirsson y Trondsen (1991) reportan que los cuatro mayores importadores de filetes congelados de bacalao para el mercado de Estados Unidos (uno de los productos pesqueros de mayor consumo en ese país) controlaban en 1987 algo más del 60\% de la oferta total de este producto en Estados Unidos. En el caso de Chile, Peña-Torres y Vespa (2005) describen significativa concentración industrial en la comercialización mayorista de la producción exportable de bacalao de profundidad, la especie marina con mayor valor unitario entre las que exporta Chile. 


\section{Descripción de la pesquería}

La pesquería de merluza austral se desarrolla en aguas interiores (canales y fiordos) y exteriores (mar abierto) dentro de la ZEE chilena, en las regiones X, XI y XII, con operación de flotas industriales y artesanales. El sector artesanal opera fundamentalmente en aguas interiores, concentrando una proporción dominante de su actividad entre las regiones X y XI (ver Figura $\mathrm{N}^{\circ}$ 1). Desde fines de 2002 los pescadores artesanales tienen derechos exclusivos para pescar ésta y otras especies de peces en la totalidad del área compuesta por las primeras cinco millas náuticas a partir del borde costero. Por otro lado, el sector artesanal tiene asignado el 50\% de la cuota global que anualmente fija el regulador pesquero para esta pesquería ${ }^{3}$. Hacia inicios de los años 2000, registros oficiales señalaban un total de 5.000 pescadores y 2.300 embarcaciones con operaciones de pesca artesanal en esta pesquería ${ }^{4}$, entre las regiones X y XII (Subpesca, 2003).

Desde los inicios de la pesquería demersal austral (PDA) ${ }^{5}$, hacia mediados de los años 70, la merluza austral ha sido una de las principales especies objetivo del esfuerzo de pesca de las flotas industriales que operan en los mares australes de Chile. El sector artesanal se incorporó a esta pesquería con fuerza creciente desde mediados de los 80.

Una fracción predominante de la producción generada por esta pesquería se destina a mercados de exportación. El valor total exportado por esta pesquería durante 2003 (sectores industrial y artesanal) fue de US\$ 65,5 millones. De éstos, US\$27,9 millones corresponden a productos en formato

${ }^{3}$ La Ley 19.849 (diciembre de 2002) autorizó por 10 años la distribución entre flotas industriales y artesanales de la cuota global anual que fija la autoridad para diferentes especies que, desde esa fecha, son reguladas bajo un sistema de cuotas individuales de captura; este sistema es aplicable sólo a la operación de las flotas industriales en cada pesquería.

${ }^{4}$ Según datos de fines de los 90, la flota industrial total que operaba en esta pesquería generaba 900 empleos directos en faenas de pesca. Otros 1.000 a 1.300 empleos directos eran generados por plantas que procesaban merluza austral, entre otras especies demersales (Sernapesca, 2001). Expertos sectoriales estiman que la proporción de empleos indirectos generados a partir del empleo laboral directo en el sector pesquero (extractivo y de procesamiento) podría fluctuar de 3 a 4 empleos indirectos por cada empleo directo.

${ }^{5}$ Así se denomina al conjunto de pesquerías de especies demersales (distintas especies de merluza y congrio dorado) que se capturan en los mares Sur-Austral dentro de la ZEE de Chile por flotas industriales y artesanales, en las regiones X, XI y XII. En el caso de las flotas industriales que operan en estas pesquerías, la mayoría de las naves poseen permisos de pesca válidos para un conjunto de las diferentes especies demersales que conforman la PDA, y concentran sus esfuerzos de pesca sobre una u otra especie, según sea la época del año. 
FIGURA N ${ }^{\circ}$ 1: PESQUERÍA ARTESANAL DE MERLUZA AUSTRAL (X y XI REGIÓN)
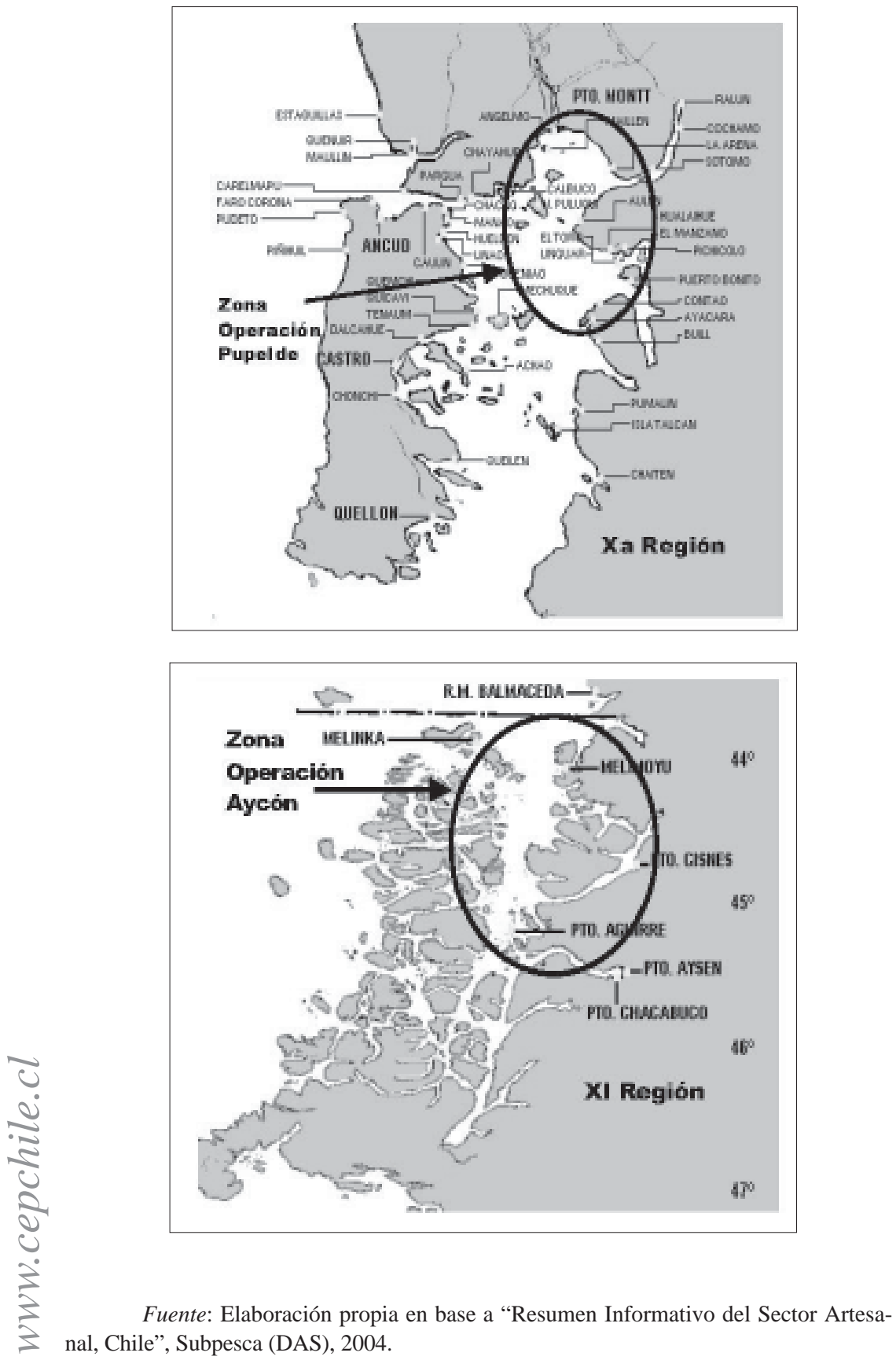
fresco-refrigerado, producción a la cual el sector artesanal entrega mayormente su pesca.

Actualmente la pesquería de merluza austral se encuentra en estado de "plena explotación" (Peña-Torres, 1997). Este régimen permite, entre otros instrumentos de regulación, cerrar el acceso a embarcaciones adicionales e imponer anualmente cuotas globales de pesca ${ }^{6}$, las que hoy se dividen en cuotas individuales para el caso de la flota industrial (PeñaTorres, 2002).

Desde comienzos de los años 90 se implementan distintas medidas de ordenamiento pesquero, con la intención de cerrar con efectividad el acceso al sector de pesca artesanal. Sin embargo, durante esa década los avances logrados fueron sólo parciales ${ }^{7}$. Por otro lado, a partir de 1995 y hasta la fecha, el sector artesanal oficialmente registrado opera bajo cuotas globales anuales de pesca (Subpesca, 1996). En el intertanto se han desarrollado diversos ajustes regulatorios, destinados a mejorar el control del cumplimiento de las cuotas asignadas. Por un lado, las cuotas globales se han dividido según distintas zonas de pesca dentro de cada región involucrada. Por otro, se han implementado asignaciones temporales por zona, definiendo en qué períodos se puede pescar en cada zona.

Junto con estas medidas, desde fines de los 90 se inició un proceso de participación creciente de los distintos grupos de pescadores artesanales en labores de autocontrol y autogestión para controlar el esfuerzo de pesca artesanal. Este aspecto se analiza en la siguiente sección.

Históricamente, la merluza austral se ha destinado en mayor proporción a elaborar productos congelados. Esto tiene que ver con las ventajas comparativas de la tecnología de pesca de las flotas industriales ${ }^{8}$. Sin embargo, desde mediados de los 90 se ha producido una tendencia de aumento en los volúmenes exportados en formato fresco-refrigerado. Durante 2003 este formato representó aproximadamente el $40 \%$ del valor total exportado de merluza austral. Este buen resultado se ha debido a los éxitos de coordinación productiva que el sector artesanal ha logrado desde inicios de los años 2000.

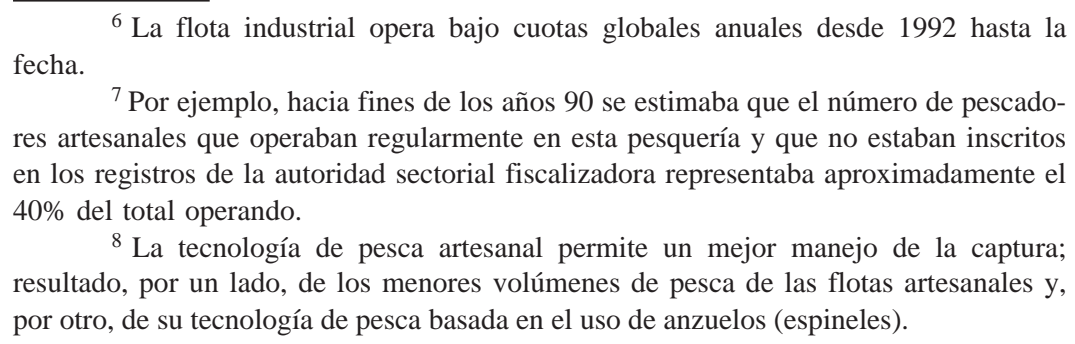

${ }^{6}$ La flota industrial opera bajo cuotas globales anuales desde 1992 hasta la fecha.

${ }^{7}$ Por ejemplo, hacia fines de los años 90 se estimaba que el número de pescadores artesanales que operaban regularmente en esta pesquería y que no estaban inscritos en los registros de la autoridad sectorial fiscalizadora representaba aproximadamente el $40 \%$ del total operando.

${ }^{8}$ La tecnología de pesca artesanal permite un mejor manejo de la captura; resultado, por un lado, de los menores volúmenes de pesca de las flotas artesanales y, por otro, de su tecnología de pesca basada en el uso de anzuelos (espineles). 
En la comercialización de merluza en fresco tanto la textura como la frescura del pescado son claves para determinar el precio de venta. En este contexto, las menores escalas de operación del sector artesanal le entregan ventajas relativas en la comercialización del pescado en fresco.

La Figura $N^{\circ} 2$ informa las fluctuaciones en los desembarques anuales de esta pesquería durante los últimos veinte años. En la década de los 80, el desembarque promedio anual bordeaba las 40.000 toneladas, alcanzándose un máximo histórico de 70.000 toneladas en 1988. Luego se generó una profunda caída en los desembarques, dada la intensa explotación pesquera. Sólo a partir de 1994 los niveles de desembarque tienden gradualmente a estabilizarse, situándose durante los primeros años de los 2000 en torno a 30.000 t/año; esto último influido por el establecimiento de cuotas anuales de pesca para cada tipo de flota.

La fase de caída en los rendimientos medios de pesca reforzó aún más los incentivos de cada pescador artesanal, dada la propiedad común de los peces, para anticipar el esfuerzo de pesca del resto de la flota. Este proceso generó concentración temporal en los flujos de oferta de la pesca artesanal, deprimiendo los precios spot de primera transacción ("precios playa”) en la compra de las capturas.

Las caídas generadas en los precios recibidos por los pescadores artesanales de merluza austral, durante los años 1996 y 1997 (ver precios

FIGURA N ${ }^{\circ}$ 2: $\quad$ DESEMBARQUE TOTAL ANUAL DE MERLUZA AUSTRAL

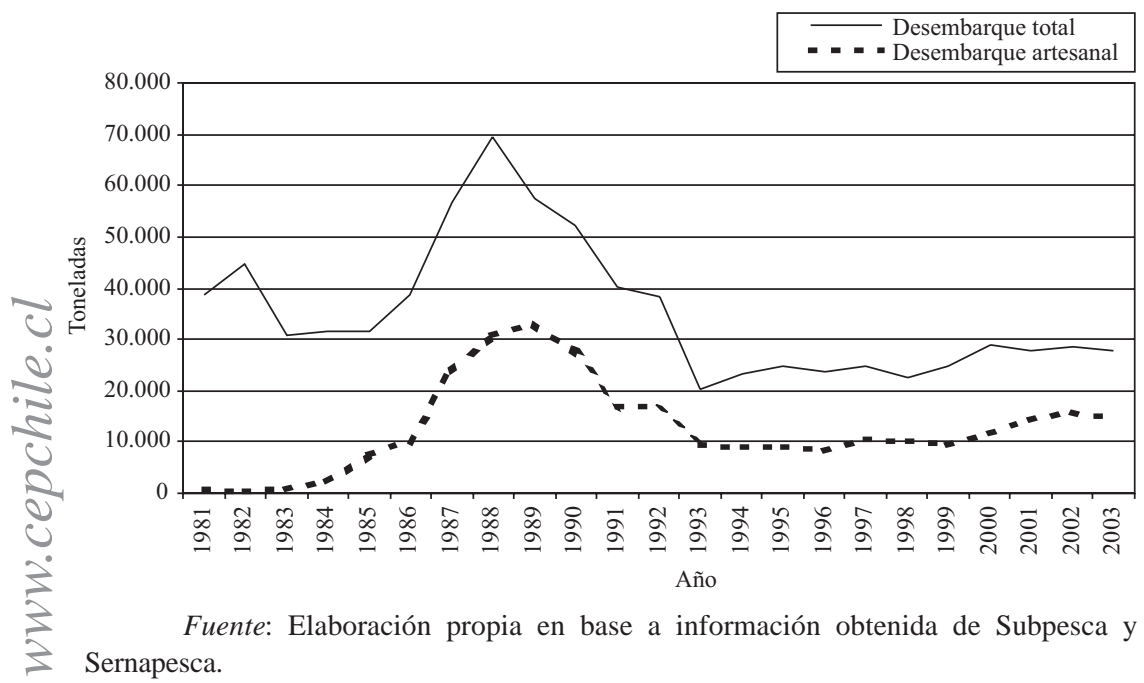


playa, Figura $\mathrm{N}^{\mathrm{0}}$ 3) jugaron un rol clave en los incentivos que luego motivaron a distintas comunidades de pescadores artesanales a iniciar esfuerzos colectivos para coordinar su esfuerzo agregado de pesca.

El principal país importador de merluza austral chilena es España. En el año 2003 este mercado compró el 94\% del valor total exportado por esta pesquería, incluyendo desembarques artesanales e industriales. En términos del valor total exportado de merluza austral en formato fresco-refrigerado, España compró el 97,4\%.

FIGURA N ${ }^{\circ}$ 3: $\quad$ PRECIO (FOB) DE EXPORTACIÓN* Y PRECIOS EN PLAYA** (US\$/KG)

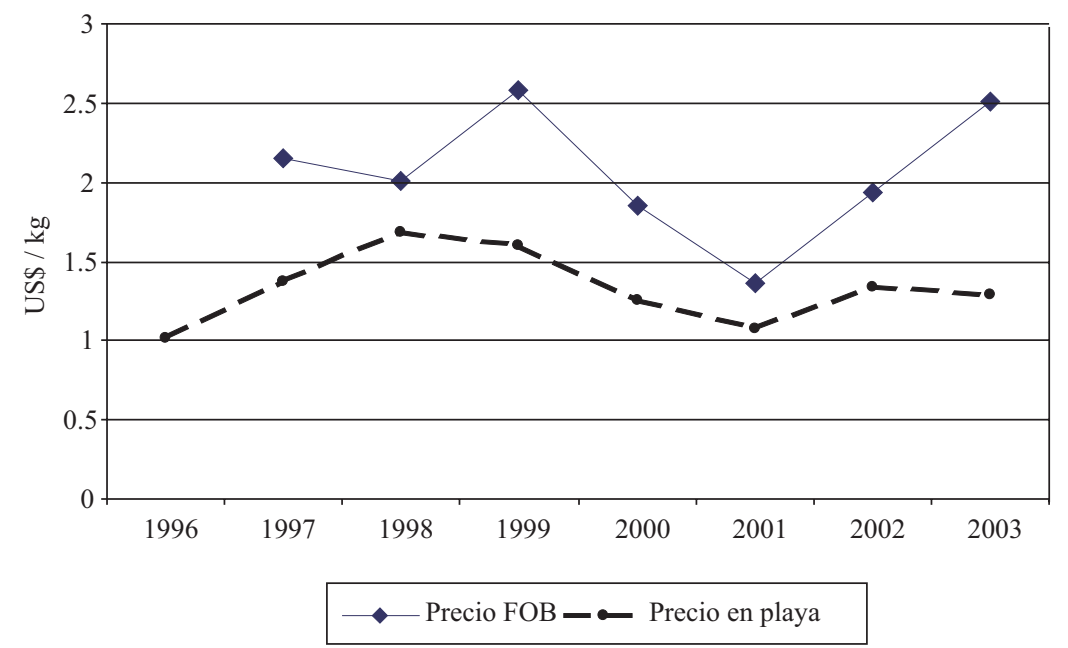

Notas: i) ${ }^{*}$ Se refiere al precio promedio de distintos productos en formato fresco-refrigerado.

ii) ${ }^{* * /}$ Promedio anual para las regiones X y XI. El precio en playa es un precio que aproxima el valor de primera transacción del desembarque. Sernapesca calcula anualmente y por especie este valor, considerando precios en playas muestreados en distintas caletas y puertos del país (fuentes de datos sobre precios playa: 1996-97, Sernapesca, 2001; 1998-2000, en base a muestreos efectuados por Sernapesca; 20012003, información recopilada por consultoras a cargo de Pescas de Investigación).

iii) Los precios de exportación y de playa no son directamente comparables. El primero se refiere a productos procesados, el segundo a pesca sin procesar. Por ejemplo, para el formato de producto (fresco-refrigerado) entero eviscerado con cabeza el coeficiente promedio de conversión se estima en tono a 97\%; para el formato eviscerado sin cabeza o HG con cola se estima en torno a $85 \%$.

Fuente: Elaboración propia en base a información obtenida de Subpesca y Sernapesca. 
En España la merluza chilena compite con al menos otras seis especies de merluza, provenientes de Argentina, Nueva Zelanda, Namibia y Sudáfrica. Estadísticas entregadas por Mercamadrid, principal mercado mayorista de transacciones pesqueras en España, señalan un aumento sostenido en las colocaciones de merluza procedente de Chile, tanto en formato de congelados como fresco-refrigerado. En el año 2003 ingresaron a Mercamadrid un total de 16.700 toneladas de merluza fresca, de las cuales Chile aportó 9.500. En 1996 el volumen ingresado de merluza austral chilena en fresco fue 4.749 t. Esta tendencia de aumento se asocia al creciente ordenamiento productivo alcanzado en la pesquería artesanal de merluza austral.

\section{Coordinación del esfuerzo de pesca}

La creciente efectividad en la coordinación del esfuerzo extractivo, del conjunto de flotas artesanales en operación constituye uno de los pilares fundamentales de los desarrollos ocurridos desde fines de los años 90 en esta pesquería. Los inicios de los esfuerzos de coordinación extractiva coinciden con la crisis productiva iniciada a fines de los 80. A continuación analizamos factores que facilitaron este proceso de cambio institucional.

\subsection{Sistema de gestión y certificación de las capturas}

Desde comienzos de los años 90 se venía produciendo en esta pesquería una caída sostenida en los rendimientos de pesca. Como resultado, en 1997 se inician diálogos entre la autoridad sectorial (Subpesca) y representantes de los pescadores artesanales encaminados a implementar un sistema de control más efectivo sobre la entrada al sector artesanal y sus niveles de captura. Estos diálogos se llevaron a cabo por iniciativa de los pescadores, con la intención de revertir la caída en los ingresos asociados a la pesca de merluza. Esta instancia de diálogo tuvo desde sus inicios una $\checkmark$ fuerte acogida entre los exportadores de merluza en fresco, dada la posibilidad que ofrecía de ordenar y racionalizar de mejor forma los flujos de pesca que debían comercializar.

Desde 1992 existía una regulación de acceso cerrado, definida de jure para el sector artesanal. Sin embargo, el sector se mantenía operando de facto bajo libre acceso. La nueva iniciativa de regulación planteaba crear un instrumento legal que permitiese controlar con efectividad el real número de botes y pescadores artesanales que participaban en esta pesquería. 
El instrumento legal utilizado consistió en implementar programas de ‘pesca de investigación'. Cada pesca de investigación determina los botes que participarán en capturar la cuota global disponible para las organizaciones de pescadores involucradas. En este esquema cada bote recibe una asignación individual de pesca que corresponde de facto a un sistema de cuotas individuales (no transferibles) de captura.

La razón fundamental de recurrir a pescas de investigación radicaba en el deseo del regulador de introducir controles más efectivos sobre la captura, en un contexto político en el que el margen de maniobra de la autoridad para usar otros instrumentos de regulación era muy limitado. ‘Pesca de investigación' es un concepto definido en la ley con el fin de evaluar los recursos pesqueros disponibles; para ello la ley faculta al regulador para introducir cuotas globales de pesca. Esto último era el verdadero objetivo del regulador al decidir implementar las pescas de investigación.

Por otro lado, y para lograr mayor efectividad con la regulación en base a cuotas globales anuales, a partir del año 1998 se distribuye la cuota asignada al sector artesanal entre dos unidades de pesquería: Norte Interior (X y XI Región) y Sur Interior (XII Región). Esta asignación se decidió en base a los desembarques históricos de cada zona.

El nuevo esquema de control basado en pescas de investigación inicia su puesta en marcha durante el año 2000. Consultoras privadas quedaron a cargo de implementar las pescas de investigación en cada zona, monitoreando el uso de las cuotas de pesca asignadas por la autoridad sectorial. La elección de empresas consultoras se decide en forma conjunta entre los representantes de los distintos grupos de pescadores y la autoridad sectorial, mediante un procedimiento administrativo de selección. Las empresas compradoras de la pesca también influyen en esta decisión, dado que son ellas quienes finalmente pagan por los servicios de las consultoras $^{9}$. Las cuotas por zonas se han subdividido mensualmente, según decisión conjunta entre las asociaciones de pescadores y Subpesca. Este esquema ha sido pensado para evitar que el total de las flotas salga simultá-

${ }^{9}$ A la fecha no se han hecho licitaciones por precio para decidir la asignación según zonas de los servicios de gestión pesquera a cargo de las empresas consultoras. Entre las razones recogidas al respecto entre fuentes consultadas estaría la intención de proveer a las organizaciones de pescadores un amplio espacio de decisión en esta materia, para consolidar su confianza en el sistema de pescas de investigación. Por otro lado, hasta el momento, ha sido reducido el número de consultoras interesadas en participar en los procesos administrativos de asignación. Actualmente operan cinco consultoras, según sean las zonas de pesca involucradas: Aycon y Universidad de Valparaíso en la XI Región, Pupelde Ltda. en la X Región (zonas de Hualaihue, Pto. Montt y Calbuco), MaresChile en la zona de Chiloé-Palena e IFOP en la XII Región. 
neamente a pescar, reduciendo así el riesgo de sobreoferta al vender la pesca.

Las consultoras financian sus servicios mediante un pago por cada kilo de pesca desembarcado en la zona bajo su control. El valor de este pago se negocia en forma ex ante entre, por un lado, las consultoras postulantes a un programa de pesca de investigación y, por otro, las empresas compradoras de la pesca y los representantes sindicales de los pescadores. Además del pago destinado a la empresa consultora a cargo, cada sindicato participante también recibe un pago (predefinido) por cada kilo de pesca de acuerdo con sus servicios de intermediación. Ambos pagos se deducen, al momento del desembarque, del valor total que las empresas compradoras se han comprometido a pagar por las capturas contratadas. Los contratos de las empresas consultoras tienen duración de un año. Su renovación requiere el apoyo de los representantes sindicales de los pescadores, el acuerdo de facto de las empresas compradoras de la pesca, como asimismo el visto bueno administrativo de Subpesca.

En la actualidad los volúmenes de pesca que compran distintas empresas son fruto de negociaciones privadas entre compradores y pescadores. Sin embargo, toda empresa interesada en comprar pesca legalmente debe estar previamente inscrita y aceptar las condiciones de operación definidas por la empresa consultora a cargo del programa de pesca de investigación. Por otro lado, el precio unitario de la pesca se determina, ex ante, como valor único para toda la cuota de pesca bajo administración de un determinado programa de pesca de investigación, en una asamblea en donde negocian, como bloques bilaterales, representantes de los pescadores y representantes de las empresas compradoras. En este sistema, las consultoras actúan como mediadores y ministros de fe para los acuerdos logrados entre compradores y los representantes sindicales de los pescadores.

En el sistema de asambleas para determinar el precio unitario de pesca, los compradores deben efectuar sus ofertas de precios en sobre cerrados. En algunas oportunidades el proceso de competencia en precios se ha efectuado de viva voz, pero este esquema no ha proliferado ${ }^{10}$. El objetivo de la asamblea es determinar un único precio de venta (por kilo de pesca)

${ }^{10}$ Una razón esgrimida por fuentes consultadas al respecto es que los pescadores tendrían la presunción de que haya acuerdos colusivos entre las principales empresas compradoras de la pesca. Esta conjetura tendría relación con el elevado grado de concentración industrial que prevalece, como veremos más adelante, en la cadena de comercialización mayorista asociada al negocio de exportación de merluza austral en fresco. 
para todos los desembarques por ocurrir dentro de un determinado programa de pesca de investigación. Un acuerdo definitivo sobre el precio de compra de la pesca requiere la aceptación consensuada de los distintos representantes de los pescadores presentes en la asamblea. En algunas ocasiones los intentos por lograr acuerdo sobre el precio de venta han sido infructuosos. Al no haber acuerdo, los pescadores han decidido no salir a pescar.

Una vez que el programa de pesca de investigación ya está operando, las empresas consultoras se encargan de registrar y certificar la información sobre las embarcaciones y los pescadores que participan en la pesca de merluza austral. También están a cargo de monitorear las artes de pesca utilizadas. Antes del programa de pescas de investigación, el único organismo fiscalizador era (la agencia pública) Sernapesca. Sin embargo, las salidas de sus funcionarios a terreno eran esporádicas, debido al escaso personal disponible para estas tareas. En la actualidad, Sernapesca continúa sus labores como fiscalizador de 'última instancia'.

En el transcurso de la evolución del sistema de pescas de investigación se han ido estableciendo diferentes mecanismos de control de la operación de las flotas. Así, este proceso ha derivado en distintas reglas de gestión y control, según sea la región de pesca. A continuación describimos algunos ejemplos.

Como parte del proceso de control bajo tutela de cada consultora, ésta envía un inspector en cada 'lancha pontonera' (la que transporta las capturas al puerto de desembarque final), con la labor de certificar las capturas obtenidas en las distintas áreas en donde ocurren faenas de pesca. Efectuada la certificación, las lanchas pontoneras se dirigen al puerto de desembarque, en donde la guía de despacho del agente comprador es visada por Sernapesca. Las listas con las capturas verificadas son luego comparadas en la oficina central de cada consultora, para detectar posibles problemas de "doble entrega", i. e. casos en donde un bote efectúa la entrega de un mismo monto de pesca autorizada en más de una zona de desembarque.

En algunas zonas (e. g., X Región zona norte), y en respuesta a la detección de varios casos de "doble entrega", a partir del año 2003 se decidió introducir un sistema de 'tickets' como complemento al sistema base de certificación ${ }^{11}$. Cada ticket tiene un original y una copia; el original queda en poder del comprador de la pesca, mientras que la copia queda para

${ }^{11}$ El sistema de tickets se implementó sólo en la zona de Hualaihue. En las zonas de Puerto Montt y Calbuco no se ha logrado implementar por falta de consenso entre los pescadores participantes. 
el sindicato que es sujeto receptor de las cuotas de pesca bajo su control. La consultora entrega los tickets a la federación de sindicatos involucrados; ésta luego los envía a sus sindicatos miembros, quienes los entregan a cada pescador, facultándolo para salir a pescar. El diseño del ticket cambia mensualmente. Al momento del traspaso de la captura a la lancha pontonera, cada pescador entrega el ticket que valida esa pesca, quedando registrado en el ticket: a) el número de matrícula de la embarcación, b) su armador (dueño), c) la tripulación, d) el total de kilos extraídos, e) el agente que compra la pesca y f) el nombre de la consultora a cargo. A la fecha, el sistema de tickets ha permitido un control efectivo del problema de "doble entrega”.

Otra de las empresas consultoras (Aycon, que administra las cuotas de pesca en la zona de aguas interiores de la XI Región) ha implementado un sistema de control totalmente computacional. Para su inicio se confeccionó una base de datos con todos aquellos pescadores que quisieran inscribirse en los registros oficiales de Sernapesca. En la actualidad la empresa consultora envía un agente acreditador en cada lancha pontonera. El acredidator dispone de un PC portátil conectado a una pesa digital. Cada pescador que participa en este sistema posee una tarjeta llamada TIPA ("tarjeta de identificación de pescador artesanal”), similar a las bancarias y cuyo código permite conocer todos los antecedentes relevantes de cada pescador.

$\mathrm{Al}$ momento de recibir la captura de un pescador, su TIPA es deslizada por un lector electrónico conectado al PC portátil, lo que activa la única pesa válida para pesar la compra (una pesa digital conectada al PC). Una vez terminado el pesaje, todos los datos relevantes quedan registrados en el PC (identificación de la embarcación, tripulación, kilos entregados, el comprador). Los datos registrados se emiten en una calcomanía con código de barras; una copia de ésta se pega al reverso de la guía de despacho, y otra copia en la caja que contiene la captura pesada. Las guías de despacho se llenan por impresión que se transmite desde el mismo PC portátil usado en el pesaje y registro. Al llegar la lancha pontonera al puerto de recalada, las guías de despacho son revisadas por otro agente acreditador (también contratado por la consultora) y luego visadas por Sernapesca.

Respecto de mecanismos de sanción a infracciones, las reglas en uso en la región de Hualaihue (X Región), vigentes a partir del año 2003, proveen un ejemplo relevante. En caso de detectarse alguna violación, las sanciones recaen sobre el comprador de la pesca fraudulenta. Por otro lado, las sanciones son graduales. Si se trata de la primera instancia de violación, el comprador de pesca ilegal debe pagar, sin derecho de apelación, 
\$ 500 mil $^{12}$ a la federación que autorizó la pesca del bote involucrado en la infracción. Si un comprador es detectado por segunda vez en una instancia de violación, debe pagar automáticamente una multa de un millón de pesos. Si la detección de transacción ilegal ocurre por tercera vez, el comprador involucrado es retirado de los registros de la consultora y pierde definitivamente el derecho a continuar participando en el sistema administrado por esa consultora.

En la región de Aysén las sanciones aplicadas por la consultora Aycon son la suspensión de la compra de pesca durante los 30 días siguientes a la fecha de cometida (por primera vez) la infracción. En caso de una segunda infracción, se sanciona con la suspensión de la compra de pesca durante el tiempo que reste del programa de pesca de investigación (estos programas tienen vigencia anual).

No obstante los avances logrados con el sistema de pescas de investigación, éste no ha estado exento de problemas. Por ejemplo, una de las primeras consultoras que operó bajo este esquema, durante los años 20002001, no logró implementar con éxito su programa de gestión.

En esa época, a las empresas interesadas en comprar se les asignaba las cuotas de pesca mediante subastas ${ }^{13}$. En el caso de esa consultora surgieron dudas sobre la transparencia de este proceso. En las zonas administradas por ella siempre ganaba las subastas la misma empresa. Como resultado, surgieron sospechas sobre negociaciones previas y pagos informales efectuados por la empresa ganadora a la consultora a cargo de la subasta. Adicionalmente, esta consultora intentó luego transformarse en agente exportador directo, una vez que su gestión de las pescas de investigación le aseguraba el abastecimiento de materia prima. Este conjunto de señales no tuvo buena acogida entre los pescadores, los que en definitiva solicitaron que esta empresa no siguiera a cargo de pescas de investigación.

El caso anterior ilustra que los procesos de avance y desarrollo institucional en esta pesquería han sido graduales. Construir y consolidar confianzas mutuas entre los distintos participantes ha sido parte fundamental de los desafíos por resolver. Para que ello ocurra, son necesarias organizaciones y agentes intermedios que faciliten el traspaso de información y un proceso eficaz de decisiones colectivas.

\footnotetext{
${ }^{12}$ Como referencia, este valor representa del 25 al 30\% del ingreso mensual per cápita que obtienen en promedio los agentes que actúan como compradores (intermediarios) directos de la pesca en esta pesquería.

${ }^{13}$ Cada comprador interesado debía ofrecer en sobre cerrado un precio de compra a la consultora a cargo del programa de pesca de investigación. La consultora debía elegir la oferta con mayor precio, y a este comprador le era asignada toda la cuota de pesca que la consultora administraba.
} 


\subsection{Organización de los pescadores}

La estructura organizacional de los pescadores artesanales se constituye por tres unidades representativas: el sindicato, las federaciones y la confederación. El sindicato es la organización local que agrupa por lo general a pescadores de una misma caleta. La federación tiene representatividad regional y está conformada por un conjunto de sindicatos. La confederación agrupa a federaciones y a sindicatos no afiliados a federaciones, y tiene carácter nacional.

La estructura organizacional depende de la región en particular. En el caso de la XI Región se aprecia la influencia de elementos económico-geográficos que han favorecido el desarrollo y eficacia de las organizaciones sindicales en sectores de pesca artesanal. Por ejemplo, el elevado grado de mutua dependencia que en general prevalece entre distintas comunidades de pescadores artesanales que operan en esta región, producto de su lejanía de centros urbanos de importancia y de su especialización (cuasi monoproductiva) en labores de pesca.

En contraste, en la X Región existe un número importante de sindicatos de pescadores que están ubicados más próximos a zonas urbanas de importancia, por lo cual disponen de mayor independencia económica respecto de la actividad pesquera. Por otro lado, en la X Región opera un número claramente mayor de pescadores artesanales que en la XI Región. Esto ayuda a entender por qué en la X Región la velocidad y profundidad de los avances logrados han sido algo más lentas que en la XI Región, en términos de consolidar mejoras en la eficiencia económica de los sistemas de gestión y autocontrol sobre el esfuerzo agregado de pesca.

En la X Región operan seis federaciones de pescadores artesanales con participación directa en la pesca de merluza austral, mientras que en la XI Región existe una sola federación de pescadores artesanales, con un significativo grado de cohesión y poder de influencia sobre sus sindicatos asociados. Los dirigentes de esta federación tienen además un fluido contacto con la consultora a cargo de las pescas de investigación en esta región ${ }^{14}$.

La federación de pescadores artesanales de la zona de Hualaihue (X Región) cuenta con el 100\% de participación de los pescadores de las zonas representadas, lo que ha favorecido su eficacia al tomar decisiones grupales. Al éxito alcanzado por esta federación han ayudado las condiciones geográficas en las cuales operan sus sindicatos miembros. La lejanía de las

\footnotetext{
${ }^{14}$ Un factor importante en lograr esta fluida comunicación ha sido que el propietario de la consultora a cargo de la gestión y control de las cuotas de pesca trabajó, previo a su rol como consultor, como pescador artesanal en esta región.
} 


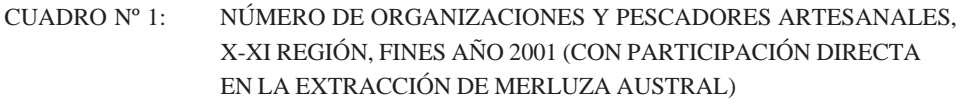

\begin{tabular}{lrr}
\hline & \multicolumn{2}{c}{ Región } \\
\cline { 2 - 3 } & $\mathrm{X}$ & $\mathrm{XI}$ \\
\hline & & \\
Federaciones & 6 & 1 \\
Sindicatos & 24 & 8 \\
Asociaciones gremiales y cooperativas & & \\
$\begin{array}{l}\text { Número de pescadores* según registros } \\
\text { de pescas de investigación (2001) }\end{array}$ & 3.660 & 1.200 \\
\hline
\end{tabular}

* Pescadores que participan directamente en la extracción de merluza austral (registros de consultoras).

Fuente: Elaboración propia en base a antecedentes proporcionados por Subpesca (2002).

comunidades de pescadores miembros de esta federación, respecto de zonas urbanas de importancia, genera mutua dependencia entre estas comunidades e incentiva la cooperación en diversos ámbitos de sus esfuerzos cotidianos $^{15}$

Para las consultoras que gestionan cuotas de pesca es fundamental contar con información adecuada y los sindicatos de pescadores son el principal vehículo para lograrlo. En la medida en que estas organizaciones tengan un adecuado nivel de eficiencia organizacional se facilita el monitoreo y control del esfuerzo productivo. La vinculación repetida entre consultoras y federaciones de pescadores ha generado creciente confianza en este programa de cuasi autogestión y control, facilitando que los pescadores sigan participando según las normas establecidas.

\subsection{Los compradores directos de la pesca}

El agente comprador es quien organiza y dirige las distintas faenas de pesca contratadas (de palabra) por él. Es responsable de abastecer y financiar a los pescadores, previo al inicio de cada faena, con combustible, artes de pesca, alimentos y otros gastos de operación. Es quien paga al

${ }^{15}$ Similar principio se observa en el fenómeno de las 'mingas' de Chiloé. En éstas, las conductas de cooperación y reciprocidad en las relaciones sociales entre miembros de una misma comunidad o de otra cercana están condicionadas por particulares sistemas de socialización, consolidados gradualmente a través del tiempo. 
pescador - una vez recibida y certificada su pesca — el precio determinado ex ante. El agente comprador goza de prestigio y poder de influencia entre los pescadores y juega un rol clave en la cadena de comercialización de la producción pesquera. Desde el punto de vista del exportador, los compradores directos de la pesca constituyen un insumo clave para el éxito de sus operaciones.

Los compradores en esta pesquería son relativamente numerosos. El número de intermediarios-compradores guarda directa relación con la dispersión geográfica de las diferentes zonas de pesca.

Cada día los botes regresan al lugar que opera como su puerto base transitorio. Obtenida la captura en cada área de pesca, los botes se dirigen a la lancha pontonera, donde los espera el representante de la empresa compradora. Junto a él, un representante de la consultora certifica la pesca. La captura se pesa, encajona y se enhiela para mantenerla en buenas condiciones; luego se deposita en la bodega, la que es sellada hasta llegar al puerto de desembarque. Recibida la pesca transportada por la lancha pontonera, el comprador paga en efectivo a los pescadores y en ese momento se saldan las cuentas pendientes originadas en los pagos por adelantado al pescador $^{16}$.

A su llegada al puerto de desembarque, la nave pontonera es recibida por funcionarios de Sernapesca, los únicos autorizados para romper el sello de su bodega. Su función es verificar el peso del desembarque y las guías de despacho. Si todo está en orden, se timbran las guías de despacho para que el producto sea trasladado a la planta de proceso y luego exportado. Las plantas de procesamiento también son fiscalizadas, como control adicional para evitar la comercialización de merluza extraída ilegalmente, la que podría estar encubierta con pesca legalmente documentada.

Para ser eficaces y competitivos, los agentes compradores necesitan el apoyo estable de una flota de botes que les abastezcan de pesca. Para lograrlo se requiere establecer relaciones de confianza con los pescadores, las que se construyen mediante la entrega repetida de servicios de apoyo al pescador, en buenas y malas temporadas de pesca. Así se establece una lógica de cooperación: el pescador apoya al proveedor-comprador con el abastecimiento de pesca, mientras el comprador apoya al pescador con abastecimiento de víveres y otros bienes y servicios, adquiribles a precios razonables sólo en zonas urbanas distantes.

${ }^{16}$ Es relativamente común que los pescadores se gasten todo el dinero obtenido por su pesca (no tienen hábitos de ahorro). En este esquema, lo predominante es que los pescadores exijan al comprador, previo a comprometer su bote para una faena de pesca aún por ocurrir, que "antes haya plata, o no hay pesca". 


\subsection{Otros factores detrás del éxito en el cambio institucional}

El desarrollo comercial de la pesquería artesanal de merluza del Sur introdujo nuevos actores económicos. A mediados de los años 80 arribó un flujo inmigratorio de nuevos pescadores, provenientes del norte del país. Una proporción no menor de estos inmigrantes llegaban de sectores diferentes de la pesca artesanal; algunos provenían directamente de trabajos heterogéneos en zonas urbanas.

Con la llegada de nuevos pescadores comenzaron a consolidarse objetivos de pesca más directamente comerciales. El enfoque hasta entonces predominante se concentraba en estrategias de subsistencia familiar. Estas nuevas prioridades más directamente comerciales influyeron en decisiones sobre las escalas de operación y la organización de la faena productiva, aproximando al sector artesanal hacia sistemas modernos de procesamiento y comercialización industrial.

Los flujos de nuevos pescadores se asentaron sobre todo en la XI Región, lo que influyó en la mayor celeridad de modernización productivoinstitucional que luego experimentó esta pesquería en la región, versus el caso de la X Región.

Otro factor que ha favorecido el cambio institucional es el elevado valor comercial de la merluza austral. Como referencia, si consideramos los 'valores de sanción' ${ }^{17}$ de las diferentes especies marinas desembarcadas en Chile el año 2001, la merluza austral tenía un valor promedio de primera transacción de \$840/kg, obteniendo la posición $\mathrm{N}^{\circ} 15$ (entre un total de 90 distintas especies) si partimos ordenando a las especies desembarcadas por aquellas con mayor valor ${ }^{18}$.

Por otro lado, la pesca de merluza del sur representa una proporción significativa del ingreso promedio por pescador en las zonas bajo análisis. Según entrevistas efectuadas el año 2003 a pescadores artesanales que operan en esta pesquería, el ingreso promedio por pescador estaría en torno

\footnotetext{
${ }^{17}$ El valor de sanción es un precio que se aproxima al valor de primera transacción (o precio en playa) del desembarque. Sernapesca calcula anualmente y por especie este valor como un promedio nacional de distintos precios playa observados a lo largo del país.

${ }^{18}$ La especie con mayor valor de sanción ese año fue el bacalao de profundidad y de Juan Fernández, con aproximadamente \$3.400/kg. Ejemplos de otras especies con elevados valores de sanción son: albacora $(\$ 2.740 / \mathrm{kg})$, centolla $(\$ 2.265 / \mathrm{kg})$, orange roughy (\$1.740/kg), lenguado (\$1.350/kg), calamar (\$950/kg) y congrio dorado $(\$ 854 / \mathrm{kg})$.
} 
a \$ 150.000 por mes, de los cuales al menos la mitad correspondería a ingresos por pesca de merluza austral ${ }^{19}$.

Por último, la creciente concentración industrial que se observa a lo largo de la cadena de comercialización de la merluza del Sur en fresco es otro importante factor que ha contribuido a promover esfuerzos de coordinación productiva en esta pesquería. La elevada concentración de mercado que se observa en la comercialización mayorista de merluza en fresco implica que existe un reducido número de intermediadores mayoristas con incentivos directos para apoyar mejoras en la coordinación y control del esfuerzo agregado de pesca. Mejoras en esta dirección les permiten a los intermediarios mayoristas negociar contratos de venta menos riesgosos y con mejores precios de venta final. Antecedentes recopilados en entrevistas a agentes expertos en esta pesquería señalan que las principales empresas exportadoras de merluza austral apoyaron desde sus inicios la implementación del sistema de gestión pesquera en base a programas de pescas de investigación.

\section{Concentración industrial en la importación mayorista de merluza fresca}

Un aspecto relevante en la comercialización de merluza austral en fresco es el elevado grado de concentración industrial que ha prevalecido durante la última década en la fase de importación mayorista al mercado predominante de exportación (España).

La importación de merluza chilena a España no opera como un segmento atomizado de mercado. Tanto en productos congelados como en el negocio del fresco-refrigerado operan importadores mayoristas que controlan importantes participaciones de mercado. En el caso del negocio en fresco, un único agente importador (que denotamos de ahora en adelante como el comercializador o agente X) tiene una participación claramente dominante en la comercialización de la merluza austral chilena ingresada en fresco a España. Según fuentes entrevistadas, este comercializador controlaría, como mínimo, el 70-80\% del total exportado de merluza en fresco desde Chile hacia el mercado español ${ }^{20}$.

\footnotetext{
${ }^{19} \mathrm{El}$ resto corresponde a ingresos obtenidos en otras pesquerías, como también en trabajos ajenos al mar (arreglo de embarcaciones y otros trabajos de tipo agrícola o maderero, e. g., leña).

${ }^{20}$ Agradecemos la información al respecto provista por personal ejecutivo de PescaChile, como también por ex ejecutivos de la empresa Consultora Pupelde Ltda.
} 
El comercializador $\mathrm{X}$ fue uno entre varios otros empresarios españoles que en la década de los 1980 llegaron a Chile para iniciar el negocio de la merluza en fresco. Sin embargo, el agente $\mathrm{X}$ fue una de las escasas excepciones que con el tiempo logró afianzar su éxito comercial en este negocio. El difícil aprendizaje de los códigos de compromiso y cumplimiento comercial por parte de los pescadores, unido al uso predominante de pagos por adelantado, por promesas de pesca muchas veces no cumplidas, llevó a que un porcentaje mayoritario del resto de entrantes a este negocio no sobreviviera.

No tenemos una explicación del todo comprehensiva del conjunto de razones para que este importador mayorista haya logrado mantener, a la fecha por más de una década, una evidente posición de dominio en el negocio de internación a España de merluza austral exportada en fresco desde Chile. No sabemos, por ejemplo, cómo operan los mecanismos de acceso a mercados cruciales de distribución y de venta minorista de productos pesqueros en España, como es el caso de Mercamadrid.

Por otro lado, hemos citado un conjunto de evidencias que sugieren significativas posibilidades de importante concentración industrial tanto en fases de proceso como en la comercialización mayorista de diferentes industrias productoras de alimentos, incluidas distintas industrias pesqueras.

En el caso específico de la pesquería en estudio podemos sugerir al menos dos hipótesis sobre posibles razones de eficiencia asignativa para la persistencia temporal de significativa concentración industrial en la fase de comercialización mayorista en el negocio de exportación de merluza austral en fresco.

En primer lugar, la importancia de garantizar una provisión regular de calidades estandarizadas de producto, en situaciones en que es costoso efectuar monitoreo directo de la calidad del producto. En este tipo de contexto, es probable que la escala eficiente de operación incluya los beneficios de crear reputación de ser un proveedor regular y confiable de calidades adecuadas de producto. Escalas expandidas de operación servirían como señal de compromiso creíble al respecto, dado el nivel de las pérdidas esperadas en caso de incumplir tal compromiso. Así, la reputación del proveedor constituiría un activo sustituto frente a otras costosas alternativas de monitoreo directo de calidades heterogéneas de producto.

En segundo lugar, es probable que también influya la presencia de importantes economías de escala en las fases de distribución, transporte y en el manejo de inventarios. 
En lo que sigue tomamos como un hecho que existe un comercializador mayorista que controla un porcentaje dominante de la merluza chilena ingresada en formato fresco a España. A partir de esto analizamos aspectos que permiten entender de mejor forma cómo se opera en esta industria y qué espacios de competencia se generan. En las siguientes secciones analizamos un conjunto de estrategias que el comercializador/importador dominante ha aplicado durante el desarrollo de sus negocios en Chile, en sus relaciones con empresas exportadoras, con agentes compradores (directos) de la pesca y en definitiva con los propios pescadores. Denominamos a este conjunto de estrategias como 'instrumentos de control vertical'.

\section{Comercialización mayorista e instrumentos de control vertical}

A continuación postulamos que los siguientes instrumentos de control vertical operan, en lo fundamental, como mecanismos que contribuyen a viabilizar el negocio de la merluza en fresco.

i) Provisión múltiple de servicios y bienes por parte de una misma contraparte comercial

A pesar de los elevados costos de transacción que determina la informalidad operante en este sector, el hecho de que un mismo agente comprador de la pesca provea múltiples servicios y bienes a los pescadores contribuye a viabilizar estos espacios de transacción. Tal como la provisión de otros servicios ya descritos, la entrega de financiamiento ex ante por parte del comprador directo de la pesca es parte de este menú contractual.

La provisión múltiple de servicios, insumos y bienes significa que el agente comprador de la pesca se transforma de facto en cuasi socio comercial del pescador; absorbiendo, por ejemplo, parte importante de los riesgos involucrados en la actividad. Nótese que los servicios provistos por el comprador de la pesca no sólo reflejan un arreglo de distribución óptima de riesgos, entre contrapartes comerciales con diferente capacidad para absorber o diversificar riesgo productivo y comercial, sino que también contribuye a aliviar diversos problemas de agencia, asociados a la frecuente ausencia de registros laborales formales y/o activos colaterizables de propiedad de los pescadores artesanales.

La provisión de múltiples servicios por parte del agente comprador crea estructuras de incentivos (para el pescador) que son complementarios 
entre sí. Por ejemplo, el efecto combinado de una y otra dimensión de intercambio comercial contribuye a mejorar las posibilidades de cumplimiento contractual en el resto de las dimensiones de intercambio. Por ejemplo, la provisión de financiamiento ex ante a los pescadores entrega al agente comprador de la pesca un instrumento extra, adicional al precio de compra, para regular los flujos deseados de materia prima.

Más adelante veremos que la real fuente de financiamiento, final y mayoritaria, de los diferentes servicios y bienes entregados ex ante a los pescadores radica en el importador dominante de la merluza chilena que es exportada en fresco a España ${ }^{21}$.

\section{ii) Acuerdos de exclusividad en el aprovisionamiento de pesca y otros flujos de producción}

Junto con entregar apoyo financiero y la provisión ex ante de diversos servicios y bienes al pescador, el agente comprador exige exclusividad en el aprovisionamiento de la pesca. No obstante, los acuerdos de aprovisionamiento exclusivo no son únicos en las transacciones directas con los pescadores. Acuerdos de exclusividad se multiplican a lo largo de la cadena de comercialización de la merluza en fresco. Junto con la relación de exclusividad entre flotas de botes artesanales y compradores (directos) de su pesca, estos últimos agentes suelen trabajar en exclusividad para una determinada empresa exportadora ${ }^{22}$. Asimismo, no es infrecuente que agentes exportadores trabajen en forma cuasi exclusiva para el importador dominante de la merluza fresca chilena que es vendida en España.

${ }^{21}$ Si el importador dominante de merluza en fresco acepta y utiliza estas distintas estrategias de fuerte control vertical, ¿por qué no le convendría integrar aun más, bajo su control patrimonial directo, las distintas fases del negocio, por ejemplo transformando a los pescadores en empleados formales a su cargo? Aparte de mayores costos de operación ligados al uso de contratos laborales formales, es probable que la estructura actual de control vertical busque además reducir costos de agencia asociados al diseño de incentivos al esfuerzo productivo. Por ejemplo, en caso de que los pescadores se transformasen en empleados formales del importador dominante al mercado español, ¿qué nivel de costos de monitoreo y control debería asumir este último agente para incentivar el cumplimiento de las obligaciones productivas de sus empleados? Responder esto requeriría considerar la significativa dispersión geográfica, junto a la atomización de la escala óptima de operación, del esfuerzo extractivo requerido por la pesca de merluza austral para el negocio de exportación en fresco.

${ }^{22}$ Son los agentes exportadores quienes proveen de financiamiento ex ante a los compradores directos de la pesca, quienes a su vez traspasan esta liquidez en forma de capital de trabajo a los propios pescadores. En definitiva, una proporción mayoritaria de los flujos de liquidez ex ante son financiados por los importadores de merluza chilena en fresco a España. 
En la pesquería bajo estudio, los acuerdos de exclusividad en el aprovisionamiento productivo cumplen un conjunto de roles. Por un lado, ofrecen al agente comprador control y mayor predictibilidad de los porcentajes significativos de la oferta de materia prima y/o de producción ya procesada. Esto favorece la posición negociadora del agente comprador frente a intermediarios que operan en fases más próximas al consumidor final. La efectividad en el control del aprovisionamiento de materia prima está respaldada por los incentivos, complementarios a tal efecto, que surgen asociados a la entrega simultánea de otros servicios y bienes al pescador. Relacionado con esto último, y dada la entrega de financiamiento ex ante a los pescadores, el contrato de exclusividad también contribuye a reducir la posibilidad de que otros agentes compradores puedan hacer free riding adquiriendo ex post la mejor pesca.

Por otro lado, la exclusividad en el aprovisionamiento también actúa como un mecanismo que reduce los problemas de selección adversa en la oferta de calidades heterogéneas de pesca (Gallick, 1984; Koss, 1999). En la medida en que exista control efectivo del cumplimiento del acuerdo de venta exclusiva por parte del pescador, este último no tendrá incentivos para seleccionar y vender calidades inferiores de producto al cumplir con el contrato de exclusividad ${ }^{23}$, puesto que no tendrá la opción de negociar, con otro agente comprador, mejores precios de compra para las unidades de producto de mayor calidad. La comercialización en fresco de la merluza implica que este problema de selección adversa también se extiende a las fases siguientes de comercialización.

Considerando la reducción del problema de selección adversa en la oferta de calidades de pesca, el acuerdo de aprovisionamiento exclusivo disminuye los costos de inspección de la calidad del producto adquirido. El acuerdo de exclusividad además disminuye los costos de búsqueda de una contraparte confiable, tanto para compradores como para oferentes.

A pesar de los argumentos previos, los acuerdos de exclusividad en el aprovisionamiento de producción en fresco también contribuyen a exacerbar los riesgos de comportamiento oportunista por parte del comprador; esto último, dada la perecibilidad del producto en intercambio como también la concentración industrial creciente que existe a medida que se avanza en la cadena de comercialización. Las siguientes dos subsecciones describen mecanismos que actúan como salvaguardas frente al riesgo de explotación oportunista por parte del agente comprador.

${ }^{23} \mathrm{El}$ contrato de aprovisionamiento exclusivo va usualmente atado, como de hecho ocurre en la pesquería bajo análisis, a un único precio promedio de compra para el total de unidades de producto ofertadas (e. g., véanse antecedentes sobre otras industrias en Kenney y Klein, 1983). 
iii) Integración vertical entre plantas procesadoras y exportadores

Aunque en el sector de procesamiento de merluza en formato frescorefrigerado prevalece la concentración industrial en un grado similar al que se da en su fase de exportación, y estando además las mayores empresas exportadoras integradas verticalmente a la propiedad de plantas de proceso, en el resto de la industria del fresco-refrigerado no necesariamente prevalecen acuerdos de aprovisionamiento exclusivo entre plantas procesadoras y agentes exportadores.

CUADRO No 2: $\quad$ PRINCIPALES PLANTAS CON PROCESO DE MERLUZA DEL SUR PARA FORMATO FRESCO-REFRIGERADO (años 2001 y 2002)

\begin{tabular}{|c|c|c|c|c|}
\hline \multirow[t]{2}{*}{$\begin{array}{l}\text { Principales plantas procesadoras } \\
\text { de fresco-refrigerado, regs. X y XI }\end{array}$} & \multirow{2}{*}{$\begin{array}{l}\text { (1) } \\
\text { con } \\
\text { I. V. }\end{array}$} & \multicolumn{2}{|c|}{$\begin{array}{c}(2) \\
\text { \% del total procesado (I) }\end{array}$} & \multirow{2}{*}{$\begin{array}{c}\text { (4) } \\
\text { \% dependencia* } \\
\text { de M. Sur (2001) }\end{array}$} \\
\hline & & 2001 & 2002 & \\
\hline Planta F1, X & $(\sim \mathrm{E} 1)$ & 12,4 & 5,8 & 15,7 \\
\hline Planta F2, X & si (E6) & 11,6 & 15,5 & 78,0 \\
\hline Planta F3, X & $(\sim \mathrm{E} 1)$ & 7,5 & 5,6 & 76,9 \\
\hline Planta F4, X & si (E7) & 7,4 & 8,8 & 44,8 \\
\hline Planta F5, X & & 5,6 & 5,7 & 65,1 \\
\hline Planta F6, X & & 1,7 & 2,1 & 30,4 \\
\hline Planta F7, X & & 1,5 & 2,9 & 2,4 \\
\hline Planta F8, X & si & 1,4 & 3,2 & 3,3 \\
\hline Planta F9, X & & 1,0 & - & 3,8 \\
\hline Planta F10, X & & - & 5,6 & \\
\hline Planta F11, X & si (E2) & 21,5 & 24,4 & 17,7 \\
\hline Planta F12, X & si $\mathrm{E}(4)$ & 14,6 & 13,4 & 85,7 \\
\hline Planta F13, XI & si $\mathrm{E}(1)$ & 13,7 & 7,1 & 11,4 \\
\hline
\end{tabular}

(I) Toneladas procesadas:

13 plantas con fresco-refrig.

$16.386,3 \quad 14.399,8$

$\%$ de mercado 5 principales plantas c/fresco-ref.

$\%$ de mercado 10 principales plantas c/fresco-ref.

$\begin{array}{ll}73,9 & 69,1 \\ 97,6 & 95,0\end{array}$

(II) Toneladas procesadas:
Total plantas (X-XII Reg.)
$18,253,0$
$16.586,2$

* \% del tonelaje procesado (año 2001) que corresponde a procesos sobre M. del Sur.

con IV.: planta que es propiedad de empresa exportadora (entre paréntesis cuál firma)

( Ei): planta sin I.V. formal, pero que opera casi exclusivamente con empresa Ei.

Nota: Las plantas que procesan merluza del Sur en la XII Región se dedican a procesar fundamentalmente capturas industriales para formatos congelados.

Fuente: Elaboración propia sobre la base de datos proporcionados por Subpesca. 
Durante el año 2001 el número total de plantas procesadoras de merluza austral correspondió a 22; de éstas, 19 trabajaban con el formato frescorefrigerado. El Cuadro $\mathrm{N}^{\circ} 2$ presenta información sobre las 13 principales plantas procesadoras de merluza en formato fresco-refrigerado ${ }^{24}$. De estas 13 plantas, las cinco principales controlaron durante los años 2001-2002 en torno al 70-74\% de la producción total de merluza en fresco. Considerando a las diez plantas principales, el porcentaje de control fluctuó esos años entre 95-98\%. Tal como lo informa el Cuadro $\mathrm{N}^{\circ}$ 3, en el segmento de empresas exportadoras los correspondientes porcentajes de concentración industrial son similares.

Junto a un conjunto de otros factores tecnológicos que condicionan el grado de concentración industrial que impera en la fase de procesamiento, se encuentran aspectos relacionados con el tipo de mano de obra requerida y la forma como se procesa la merluza en fresco. Por un lado, las técnicas de procesamiento para formatos de merluza en fresco precisan mano de obra especializada, de forma tal que se ejecuten los cortes que permitan un mayor rendimiento de materia prima, manteniendo a la vez la calidad del producto final.

Por otro lado, operar eficientemente en este negocio requiere una adecuada logística, control y coordinación de volúmenes significativos y simultáneos de pesca, como también de un número importante de mano de obra, en su mayoría especializada. La entrada de materia prima puede ocurrir en cualquier hora (día o noche). Así, se debe contar con un determinado número mínimo de personal calificado, eventualmente disponible las 24 horas. La falta de personal y/o de la rotación de éste pueden implicar elevados costos en pérdida de calidad y/o de rendimientos en la producción.

Respecto a la presencia de estructuras productivas verticalmente integradas en su propiedad, de los Cuadros $\mathrm{N}^{\text {os }} 2$ y 3 se desprende que al menos las cinco principales empresas exportadoras poseen planta propia para procesar merluza en formato fresco-refrigerado. Así, las plantas sujetas a integración vertical tienden a coincidir con aquellas que procesan los mayores porcentajes de merluza en fresco. En el caso de las plantas F1 y F3, éstas procesan producción que mayormente se exporta por la empresa E1 (Cuadro $\mathrm{N}^{\circ}$ 3).

${ }^{24}$ La producción del resto de plantas en este formato de procesamiento no representa un porcentaje relevante. El procesamiento en esencia consiste en cortar, limpiar y empacar el producto para formatos frescos-refrigerados H-ON (merluza con cabeza), HGT (merluza sin cola y sin cabeza), HG (merluza sin cabeza), filetes y cocochas. 
En el resto de la industria de merluza en fresco tienden a prevalecer contratos más bien de corto plazo (contratos de maquila) entre plantas y empresas exportadoras. En estos casos, diversificar entre distintas especies y formatos de procesamiento (como ejemplo, ver columna 4 en Cuadro $\mathrm{N}^{\circ} 2$ ) es una de las formas de reducir los riesgos asociados a la perecibilibidad de la producción en formato fresco-refrigerado.

Por lo tanto, en aquellas plantas donde mayor es el porcentaje de dependencia respecto de procesos en base a merluza del Sur en fresco, las respuestas contractuales frente a riesgos asociados a la perecibilidad del producto tienden a fluctuar entre integración vertical total y otros mecanismos de fuerte control vertical. Por ejemplo, acuerdos de casi total exclusividad en el aprovisionamiento para el importador dominante de merluza en fresco ingresada a España, combinados con la entrega de otros servicios (e. g., financiamiento ex ante) provistos por el mismo agente importador. En el caso de las plantas F2 y F12, ambas están integradas a la propiedad de empresas de exportación que operan bajo prácticamente total exclusividad para proveer merluza en fresco al agente comercializador $\mathrm{X}$.

\section{iv) Determinación ex ante del precio de compra de la pesca}

La determinación ex ante del precio de la pesca representa un resguardo, a favor del pescador, frente al riesgo de comportamiento oportunista por parte del comprador, dados la perecibilidad del producto en transacción, lo concentrado del segmento comprador de la pesca y el predominio de acuerdos de aprovisionamiento exclusivo respecto de la pesca.

Similar rol de resguardo puede atribuirse al hecho de que el agente comprador provea de una multiplicidad de servicios y bienes al pescador. Actuando de esta forma, el comprador se transforma de facto en una especie de 'socio parcial' del pescador frente a las diversas incertidumbres que enfrenta el esfuerzo productivo en esta actividad extractiva. La mutua dependencia comercial de ambas contrapartes tiende a reducir los incentivos del comprador para actuar en forma oportunista en desmedro del pescador.

En lo que sigue analizamos antecedentes adicionales sobre cómo opera el negocio de exportación de merluza austral en fresco. Buscamos aportar información sobre el tipo de competencia de mercado que existe en el segmento de exportación de esta industria; en particular, de qué forma ocurre la interacción comercial entre las principales empresas exportadoras y el agente importador dominante (comercializador $\mathrm{X}$ ). 


\section{Participaciones de mercado en el segmento exportador de merluza en fresco}

El Cuadro $\mathrm{N}^{\circ} 3$ informa las participaciones de mercado de las mayores empresas exportadoras durante el período 1997-2004. Incluimos en este grupo a aquellas empresas que han alcanzado escalas significativas de operación, igualando o superando una cota mínima de volumen de exportación equivalente a 500 toneladas/año ${ }^{25}$. También informamos la participación de mercado de las cinco y diez principales exportadoras en cada año, junto con el número total de empresas que registran operaciones de exportación de merluza del Sur desde Chile, en formato fresco-refrigerado.

Durante el período 1997-2004 el segmento de empresas exportadoras de merluza en fresco presentó significativa concentración industrial. La participación de las cinco mayores exportadoras fluctuó entre 62 y 87\%, mientras que las diez principales empresas controlaron entre el 86 y 97\%. Asimismo, durante este período declinó el número de empresas exportadoras. Hacia fines de los 90 operaban cerca de 50 empresas, mientras que el 2004 su número cayó a 26.

Adicionalmente, el Cuadro $\mathrm{N}^{\circ} 3$ reporta cambios no despreciables en las participaciones de mercado de las mayores empresas exportadoras. $\mathrm{Y}$ esto en un contexto donde existe un número significativo de exportadores de merluza en fresco con operaciones registradas durante los años 19972003. En este período 177 diferentes personas jurídicas registran operaciones de exportación de merluza austral en fresco (datos de Aduana). Ahora bien, si consideramos a las diez exportadoras de merluza en fresco con mayor participación durante 1987 (año próximo al inicio del auge de exportación en esta pesquería), sólo dos de ellas continúan en este negocio, mientras que sólo una de ellas fue parte del grupo de las mayores exportadoras durante los años 1997-2004. Por último, si nos concentramos en el grupo de diez empresas reportadas en el Cuadro $\mathrm{N}^{\circ} 3$, sólo tres de ellas mantienen en forma continuada volúmenes de exportación por sobre las 500 t/año durante el período 1997-2004.

En lo que sigue veremos que este patrón de rotación entre las principales empresas exportadores está relacionado con (aunque no necesariamente causado por) las intervenciones del importador dominante al mercado español.

${ }^{25}$ Como referencia, el promedio (por empresa) de toneladas anuales exportadas de merluza en fresco por la industria chilena ha sido: 1997, 154 t; 1998, 184 t; 1999, 203 t; 2000, 248 t; 2001, 279 t; y el 2002, 316 t. 
CUADRO N ${ }^{\circ}$ 3: $\quad$ PARTICIPACIÓN DE MERCADO DE LAS MAYORES EMPRESAS

EXPORTADORAS (período 1997-2004)

(Según valores exportados de merluza del Sur en formato fresco-refrigerado)

\begin{tabular}{|c|c|c|c|c|c|c|c|c|}
\hline \multirow[t]{2}{*}{ Empresa exportadora } & \multicolumn{8}{|c|}{ Participación de mercado (\%) } \\
\hline & 1997 & 1998 & 1999 & 2000 & 2001 & 2002 & 2003 & $2004 *$ \\
\hline Exportadora 1 (E1) & 5,8 & 8,6 & 38,0 & 40,3 & 10,2 & 12,2 & 10,7 & 12,6 \\
\hline Exportadora 2 (E2) & 7,6 & 8,7 & 20,4 & 8,6 & 7,1 & 8,9 & 11,2 & 16,8 \\
\hline Exportadora 3 (E3) & 14,9 & 11,7 & 0,0 & 0,0 & 0,0 & 0,0 & 0 & 0 \\
\hline Exportadora 4 (E4) & 14,4 & 8,0 & 4,1 & 6,6 & 12,3 & 15,1 & 21,2 & 13,8 \\
\hline Exportadora 5 (E5) & 25,6 & 20,8 & 0,0 & 0,0 & 0,0 & 0,0 & 0 & 0 \\
\hline Exportadora 6 (E6) & 0 & 11,7 & 10,5 & 14,2 & 22,8 & 15,3 & 13,8 & 14,4 \\
\hline Exportadora 7 (E7) & 0 & 0 & 13,9 & 12,4 & 15,8 & 11,3 & 10,5 & 10,1 \\
\hline Exportadora 8 (E8) & 0 & 0 & 0 & 0 & 5,8 & 7,3 & 0 & 0 \\
\hline Exportadora 9 (E9) & 0 & 0 & 0 & 0 & 0 & 8,7 & 12,9 & 9,1 \\
\hline Exportadora 10 (E10) & 0 & 0 & 0 & 0 & 5,0 & 4,4 & 5,9 & 5,9 \\
\hline \% mcdo. resto de exportadoras & 31,7 & 30,5 & 13,1 & 17,9 & 21,0 & 16,8 & 13,8 & 17,3 \\
\hline Número total de exportadoras & 52 & 48 & 47 & 42 & 43 & 37 & 35 & 26 \\
\hline$\%$ mercado de 5 principales firmas & 68,2 & 61,5 & 86,9 & 82,1 & 68,2 & 62,6 & 69,8 & 67,7 \\
\hline$\%$ mercado de 10 principales firmas & 87,6 & 90,1 & 96,7 & 97,3 & 89,0 & 85,7 & 93 & 94,5 \\
\hline Total valor exportaciones (miles US\$) & 17.158 & 17.672 & 24.684 & 19.315 & 16.255 & 22.611 & 27.486 & 19.568 \\
\hline
\end{tabular}

* Según valores acumulados a septiembre de 2004.

Fuente: Elaboración propia basándose en datos de IFOP y ProChile.

Ya hemos señalado que una proporción mayoritaria de los embarques de merluza austral en fresco es comercializada e internada a España por el agente $X^{26}$. Por otro lado, parte de los principales agentes exportadores operan bajo acuerdos de exclusividad en el aprovisionamiento de producción en fresco para el comercializador X. La totalidad de este último grupo de agentes exportadores se iniciaron en el negocio de la merluza austral como compradores directos de pesca. Luego, a través de los años y con el apoyo financiero directo del comercializador X, han evolucionado hasta transformarse en agentes exportadores.

${ }^{26}$ Este hecho ha sido corroborado por ejecutivos superiores de la importante empresa exportadora E1. Como corroboración adicional al respecto, la siguiente información fue verificada vía entrevistas en terreno: la empresa Novameditpesca es actualmente una de las mayores compradoras de merluza artesanal. En enero y febrero de 2005 fue la empresa que registró el mayor tonelaje de compra de pesca de merluza en la zona de Hualaihue, Pto. Montt y Calbuco. Esta empresa opera fundamentalmente con financiamiento entregado por el comercializador X y exporta vía este importador al menos el 70\% de su producción de merluza austral en formato fresco. 


\section{Interacción entre agentes exportadores y el importador dominante}

En esta sección analizamos el patrón de interacción comercial que el importador dominante ha desarrollado con algunas de las principales empresas exportadoras. En particular, nos concentramos en las empresas E4, E5, E9 y E10. Este grupo de empresas, junto con E1, comercializa prácticamente la totalidad de su producción de merluza en fresco vía el agente X. Sabemos que al menos las cuatro primeras empresas aludidas operan bajo acuerdos de total exclusividad con el agente importador X. Este conjunto de empresas (E1 incluida) ha controlado durante 1997-2004 entre el 30 y el 40\% del total de las exportaciones chilenas de merluza en fresco (Cuadro $\mathrm{N}^{\circ} 3$ ).

Respecto a otros exportadores que también comercializan sus ventas de merluza fresca a España en forma significativa vía el agente importador $\mathrm{X}^{27}$, permitiendo así que este agente controle al menos el $70-80 \%$ del total exportado a España de merluza austral en fresco, no podemos asegurar que también operen con el agente $\mathrm{X}$ bajo contratos de aprovisionamiento exclusivo.

Durante la última década las cuatro primeras empresas aludidas han mantenido acuerdos de exclusividad en el aprovisionamiento de merluza fresca para el agente importador $\mathrm{X}$, junto con apoyo financiero directo de este último para financiar su capital operacional. Sin embargo, el apoyo del agente $\mathrm{X}$ a estos distintos exportadores no ha sido siempre constante para todos.

Quizás el caso más ilustrativo sea la evolución de la empresa E9. Su actual dueño comenzó, en los primeros tiempos de la exportación de merluza austral, como comprador directo de pesca para el agente X. Gracias a una amplia red de contactos en el mundo de la pesca artesanal de merluza austral en la X Región, este operador rápidamente se transformó en uno de los más importantes compradores de merluza en la región ${ }^{28}$. Fruto del éxito

${ }^{27}$ Otras importantes empresas exportadoras que operan en forma significativa con el agente importador X son E2, E6 y E7. Respecto al resto del volumen de merluza austral en fresco exportado desde Chile, las empresas exportadoras involucradas parecieran ser en general exportadores incipientes; si éste fuese el caso, no parece improbable que al menos parte de su producción sea también comercializada vía el agente $\mathrm{X}$.

${ }^{28}$ Este operador es conocido en el rubro por el apodo de "20 millones", en alusión a su frecuente manejo de importantes sumas de dinero en efectivo. A inicios de los años 90, con las rentas generadas por el negocio de la merluza, este agente construyó una planta de proceso de alta tecnología, sorprendente para lo que hasta ese momento se conocía en Puerto Montt. 
logrado, el comercializador X lo apoyó con creciente financiamiento, incentivando la expansión de sus operaciones. Hacia fines de los años 80 ya operaba como exportador, bajo acuerdo de aprovisionamiento exclusivo para el agente $\mathrm{X}$.

A comienzos de los años 90, cúspide de su apogeo comercial, este operador intentó desarrollar mayor autonomía en sus operaciones con el comercializador X. Como parte de este proceso, el dueño de E9 comenzó a requerir mejores precios de compra para su producción. En respuesta, el agente $\mathrm{X}$ le quitó su apoyo financiero y expandió sus operaciones con otros proveedores de merluza. Afectado por la pérdida de apoyo del agente X, el controlador de E9 tuvo que retirarse del negocio en 1993 porque afrontaba una fuerte crisis de liquidez.

Parte del negocio de E9 fue luego continuada por el hijo del ex dueño de E9, que actuaba como comprador de pesca para la empresa exportadora E5. El control de esta empresa quedó en manos de un agente de confianza del comercializador X. Así, la empresa E5 continuó operando bajo acuerdos de aprovisionamiento exclusivo para el agente $\mathrm{X}$.

Sin embargo, el agente $\mathrm{X}$ también comenzó a apoyar más decididamente las operaciones de otros exportadores, entre éstos E4, empresa que inicialmente tenía operaciones sólo en la XI Región. El agente X entregó financiamiento a esta empresa para que ampliara sus compras de pesca a la X Región. En años posteriores esta empresa llegó a encabezar la lista de principales exportadoras de merluza en fresco (Cuadro $\mathrm{N}^{\circ} 3$ ).

La empresa E5 dejó de exportar merluza en fresco a partir del año 1999, luego de alcanzar una participación de 21\%. Su participación de mercado fue absorbida fundamentalmente por E1. Esta empresa también comercializa su producción de merluza en fresco mayormente vía el agente $\mathrm{X}$, aunque no podemos asegurar que ello ocurra bajo un acuerdo de aprovisionamiento exclusivo.

La dinámica recurrente en las interacciones descritas implica, en una primera etapa, la entrega de creciente apoyo financiero y comercial del importador $\mathrm{X}$ hacia agentes que han sido exitosos como compradores directos de pesca. Luego éstos pasan a operar como agentes exportadores, usualmente bajo acuerdos de exclusividad en el aprovisionamiento para el agente $\mathrm{X}^{29}$.

${ }^{29}$ Otro ejemplo de esta dinámica es la empresa E10. Su actual dueño fue inicialmente un exitoso comprador de pesca para exportadores de merluza, a principios de los años 90. Actualmente E10 se encuentra entre el grupo de empresas que exportan por sobre las 500 toneladas anuales. 
No disponemos de información que nos permita analizar con mayor detalle el tipo de competencia que prevalece en el segmento de exportadores de merluza en fresco. Los cambios en las participaciones de mercado de los principales exportadores pueden deberse a diferentes razones. Una posibilidad podría ser que las variaciones en el apoyo del agente $\mathrm{X}$ a distintos exportadores reflejen una estrategia tipo 'dividir para luego reinar', i. e. buscando evitar que algún exportador se transforme en real competencia en el dominio de mercado que $\mathrm{X}$ ostenta. Una hipótesis alternativa sería que esos cambios en los apoyos entregados por X buscan mayor diversificación, y por tanto menor riesgo comercial, en el portfolio de sus proveedores de merluza en fresco. Otra posibilidad es que los vaivenes en las participaciones de mercado sean simplemente resultado de fuerte competencia entre los propios exportadores. La evidencia disponible no nos permite discriminar entre la relevancia empírica de éstas u otras posibles hipótesis.

\section{Entrada a la comercialización e importación mayorista de merluza en fresco}

Por más de una década el agente $\mathrm{X}$ ha logrado mantener una posición dominante en el negocio de importación de merluza austral exportada en fresco a España. Una posibilidad es que la concentración industrial vigente refleje un arreglo asignativo óptimo para efectos de viabilizar un funcionamiento adecuado del negocio. Quizás la elevada participación de mercado del agente $\mathrm{X}$ es consecuencia de ventajas comparativas sobre otros potenciales competidores. Una hipótesis alternativa es que la concentración observada esté asociada con rentas extranormales, protegidas por barreras 'artificiales' (anticompetitivas) de entrada al sector.

Si bien la evidencia disponible no nos permite desarrollar un análisis comprehensivo ni mucho menos definitivo al respecto, en esta sección describimos evidencia útil para el desarrollo de futuros análisis más detallados sobre las hipótesis arriba descritas. A continuación analizamos antecedentes relacionados con la posibilidad de que existan barreras de entrada al negocio de comercialización mayorista de merluza en fresco.

Un primer aspecto de interés es que durante toda la década de los 90 y hasta la fecha ocurrió una única real amenaza de competencia por parte de un entrante al negocio de comercialización mayorista de merluza austral en fresco, en el mercado dominante de exportación (España). El nuevo entrante fue la empresa española Caladero, cuya principal línea de negocios ha sido 
tradicionalmente la internación de merluza en formato congelado al mercado español ${ }^{30}$.

Entre los años 1998 y 2002, Caladero compitió directamente con el agente $\mathrm{X}$ en la internación a España de merluza en fresco exportada desde Chile y se valió de la empresa E8 como su principal agente exportador (Cuadro $\mathrm{N}^{\circ}$ 3), proveyéndole de apoyo financiero. Durante los años 2001-2002 Caladero llegó a transformarse en una fuerte amenaza para el control del agente $\mathrm{X}$ en este segmento del negocio de la merluza austral ${ }^{31}$.

Para enfrentar la competencia de Caladero, el agente $\mathrm{X}$ recurrió a un conjunto de medidas. Primero reclutó nuevamente al dueño inicial de la empresa E9 como agente exportador bajo acuerdo de total exclusividad, dada su valiosa red de contactos entre los pescadores merluceros. Con el apoyo financiero de $\mathrm{X}$, este operador rápidamente retorna (desde 2002 y hasta la fecha) al grupo de los mayores exportadores de merluza austral en fresco (Cuadro $\mathrm{N}^{\circ} 3$ ).

El agente $\mathrm{X}$ además dirigió un conjunto de otras medidas para neutralizar la competencia de Caladero en el negocio del fresco. Por ejemplo, la competencia con Caladero y su empresa coligada E8 gatilló fuertes guerras de precios de compra por la pesca de merluza austral, tanto en la X como en la XI Región, competencia que habría sido particularmente fuerte durante el año $2001^{32}$.

Adicionalmente, Caladero enfrentó un conjunto de otros impedimentos para comprar merluza: recursos de protección interpuestos con el fin de impedir la participación de E8 en los procesos de compra de pesca (programas de pesca de investigación); instigación de controles exhaustivos, por parte de agentes fiscalizadores, sobre las plantas que procesaban pesca para la firma E8; junto con aumentos en las comisiones pagadas a las organizaciones de pescadores artesanales, para asegurar la pesca lograda por sus miembros.

${ }^{30}$ Adicionalmente, la empresa Caladero tiene una importante flota de barcos operando en la pesca de merluza en Namibia. Hoy Caladero también opera en Chile como comercializador de otros productos pesqueros para exportación hacia el mercado español.

${ }^{31}$ En el año 2001 E8 exportó 619,2 toneladas de merluza austral en fresco, luego de un muy rápido crecimiento en sus operaciones en este negocio; durante los años 1998 y 1999 exportó 8,5 y 7,5 toneladas, respectivamente.

${ }^{32}$ La Figura $N^{\circ} 3$ reporta para el año 2001 una clara reducción en la brecha entre el precio promedio de exportación (productos fresco-enfriados) y el precio promedio playa. Esta brecha la podríamos interpretar como una proxy indirecta de los márgenes obtenidos en los servicios de intermediación, suponiendo constantes los coeficientes técnicos de conversión a producto procesado. 
En definitiva, este conjunto de acciones derivaron en fuertes pérdidas para Caladero que liquidaron su intento por consolidar posiciones en el segmento de intermediación controlado por el comercializador X.

¿Por qué fracasó la entrada de Caladero al negocio de la merluza en fresco? Dada la importante experiencia de esta empresa como comercializador internacional de productos pesqueros, parece poco razonable argumentar que esto pudo estar relacionado con su desconocimiento de esta área de negocios. Por otro lado, la interacción comercial desarrollada con la exportadora E4, y sus estrategias de adquisición de pesca mediante intermediarios con experiencia y reputación en el medio regional, también parecen descartar la opción de ventajas significativas del agente $\mathrm{X}$ en el costo de adquisición de la pesca. Tampoco parece razonable suponer que existían claras desventajas de costos, en desmedro de Caladero, en las condiciones de acceso a fuentes formales de financiamiento.

Tal vez una importante ventaja competitiva del importador $\mathrm{X}$ se deba al acceso a redes claves de distribución y/o de venta minorista en los mercados finales de destino. Quizás el tamaño del mercado es tal que, dadas las posibles economías de escala en las fases de distribución y comercialización mayorista, no exista espacio adicional para otro competidor de relativo similar tamaño en la fase de importación de merluza fresca a España. En todo caso, en principio parece extraño presuponer que un competidor con experiencia como Caladero, conocedor del negocio de comercialización al por mayor de productos pesqueros en España, haya errado en forma importante al evaluar las escalas razonables de operación en el mercado de merluza en fresco. Lamentablemente, respecto de este conjunto de posibilidades no logramos obtener mayor información.

Sólo resta añadir otra opción mencionada por fuentes entrevistadas: la posibilidad de actividad ilegal en esta área de negocios ${ }^{33}$. En concreto, captura ilegal (por sobre las cuotas asignadas) y figuras de exportación ilegal junto con evasión impositiva al ingresar los productos a España. En caso de existir ganancias obtenidas vía transacciones ilegales, éstas podrían facilitar la defensa de firmas que ya operan en este tipo de negocios, frente a la entrada de nuevos competidores.

En relación con esta última posibilidad, es posible citar las siguientes evidencias. Primero, y respecto del mercado de comercialización español, la

${ }^{33}$ Fuentes que nos han autorizado a ser citadas al respecto son: Francisco Ojeda, ex ejecutivo de la Consultora Pupelde Ltda., y Renato Céspedes, staff permanente de IFOP, que ha estado a cargo de dirigir programas de pesca de investigación en la pesquería artesanal de merluza del sur en la XII Región. Otras fuentes que solicitaron anonimato también mencionaron esta posibilidad, aunque ninguna proveyó pruebas al respecto. 
Revista Mar (1999), española, denuncia la existencia de fraudes al consumidor $^{34}$ en cuanto a la verdadera especie en venta. Allí se menciona que la merluza austral chilena en ocasiones se vendería en España como merluza de pincho (del mar Cantábrico); esta última especie tiene un mayor valor de transacción relativo al de su par chilena ${ }^{35}$. Esta misma práctica es también citada en Matamala (2004), informe financiado por Sercotec que analiza la cadena de comercialización de la merluza austral chilena exportada al mercado español.

Otra motivación para realizar fraude comercial sería evadir impuestos de importación al ingresar la producción a España ${ }^{36}$. Una forma de lograr esto podría consistir en rotular en forma fraudulenta parte de la producción exportada desde Chile; por ejemplo, usando rótulos de productos más baratos. Al respecto, durante el año 2002 personal de Sernapesca, que efectuaba labores de fiscalización en el aeropuerto de Santiago, descubrió flujos de exportación de merluza austral en fresco que correspondían a producción en formato 'sin cabeza'; sin embargo, el embarque estaba facturado como 'producto entero con cabeza'. El formato 'sin cabeza' tiene mayor valor comercial $^{37}$. No disponemos de evidencia adicional que nos permita evaluar con mayor rigor la relevancia empírica de las posibilidades de fraude aquí descritas.

\section{Conclusiones}

A continuación comentamos algunas lecciones que se derivan de esta investigación junto con temas de discusión que implican desafíos para investigación futura.

En primer lugar, hemos descrito un conjunto de factores que en la pesquería de merluza austral han constituido incentivos importantes para el éxito de acción colectiva por parte de organizaciones de pescadores artesanales. Entre ellos, el elevado valor comercial de la especie capturada, la crisis de productividad que experimentó esta pesquería durante los 90 , que

${ }^{34}$ Citando un informe de Greenpeace, con base en trabajos realizados por el Instituto de Investigaciones Marinas del Centro Superior de Investigaciones Científicas (CSIC) con sede en Vigo, Galicia.

${ }^{35}$ Durante los años 2002-2003, el precio de la merluza austral chilena correspondió a cerca del $40 \%$ del precio de la merluza de pincho, en transacciones reportadas por Mercamadrid.

${ }^{36}$ En la actualidad este tipo de producto pesquero paga en España un arancel de importación en torno al 12\% del valor CIF del producto importado.

${ }^{37}$ Agradecemos al Sr. Manuel Ibarra, jefe de Fiscalización de Sernapesca en la Región Metropolitana, por describirnos este caso. 
los ingresos por pesca de merluza austral representen una proporción importante del ingreso medio por pescador, que exista significativa concentración industrial a lo largo de la fase de comercialización mayorista de la merluza austral en fresco, y la necesidad de acción colectiva en comunidades alejadas de centros urbanos y con especialización casi exclusiva en labores de pesca. La relevancia de estos factores en otros contextos de pesquerías artesanales condiciona la posibilidad de replicar en ellas similares experiencias de acción colectiva y autogobierno por parte de organizaciones de pescadores.

Junto con lo anterior, esta investigación también delata vacíos importantes en el conocimiento disponible de otros condicionantes de la eficiencia de organizaciones intermedias en sectores de pesca artesanal. Por ejemplo, se sabe muy poco sobre el desarrollo y ejercicio de liderazgo en estos sectores; o sobre los incentivos laborales y de producción resultantes de un conjunto disperso de leyes asociadas a temas de representación sindical y gremial. Estas áreas de análisis constituyen desafíos relevantes para investigación futura.

Una segunda área de discusión se relaciona con la significativa concentración industrial constatada en la comercialización mayorista de merluza austral en fresco. Esta característica refleja un patrón de estructura industrial que claramente va más allá de esta pesquería en particular. Hemos citado evidencia en similar dirección para la comercialización mayorista de bacalao de profundidad (Dissostichus eleginoides) hacia mercados de exportación; también ha sido sugerido un contexto similar para la comercialización mayorista de la producción chilena de locos (Concholepas concholepas) de exportación (Rivas, 2000). Sería de interés corroborar si este tipo de estructura industrial tiene aplicación más general, incluyendo el caso de otras industrias de producción perecible y con calidades heterogéneas de producto. Sería igualmente de interés entender de mejor forma por qué se observa concentración industrial en este tipo de industrias, no sólo en sus fases de procesamiento sino también en segmentos de comercialización mayorista.

Ev el presente estudio hemos sugerido argumentos de eficiencia asignativa, como también asociados al ejercicio de poder de mercado, respecto de posibles explicaciones de la persistencia temporal de concentración industrial en la comercialización mayorista de merluza en fresco. Sin embargo, dada la información hoy disponible, no hemos podido discriminar en forma robusta la relevancia empírica de las diferentes hipótesis sugeridas. Dada la importancia en Chile de este tipo de industrias, investigación adicional en esta dirección, incluyendo el caso de industrias similares, aportaría conocimiento útil y relevante. 
Relacionado con lo anterior, en años recientes han aumentado en forma importante los recursos públicos destinados a programas de desarrollo productivo para sectores de pesca artesanal. En la actualidad el conjunto de estos programas (Fosic, Sercotec, FNDR, FFPA, Corfo y Sence) financia en torno a US\$ 7,5 mills./año ${ }^{38}$. Parte no menor de estos recursos se financian con las patentes anuales cobradas a la flota pesquera industrial. En este contexto han surgido propuestas para apoyar la comercialización directa (a mercados de exportación) por parte de pescadores artesanales.

Dada la evidencia de concentración industrial en estos segmentos de mercado, surgen preguntas sobre la factibilidad de que existan ganancias asignativas asociadas a este último tipo de política pública. En caso de que existiesen ganancias netas, ¿interesaría quizás apoyar la consolidación de flujos de exportación, para así alcanzar escalas de operación que sean competitivas a nivel internacional? Entender de mejor forma cómo operan los mercados de comercialización mayorista de producción exportable perecible contribuiría a tener evaluaciones más robustas de la conveniencia social de las actuales políticas de fomento productivo y comercial en sectores de pesca artesanal.

Un tercer tema se refiere a las razones para que exista comercio informal en este tipo de sector productivo. Al respecto hemos presentado argumentos relacionados con el ahorro de costos de transacción. También nos hemos referido a la posibilidad de que parte de la informalidad se deba a intentos de evadir costos asociados al intercambio formal y legal. Lamentablemente no hemos logrado reunir suficiente información de forma que nos permita discriminar en forma robusta sobre la validez relativa de una y otra línea de argumentos.

Asociado a esta última área de debate surgen preguntas adicionales de investigación. Por ejemplo, ¿existen dimensiones de las transacciones informales observadas que convendría intentar formalizar? En caso de que sí existan, ¿qué estrategias de incentivos y/o de control convendría utilizar para promover mayor formalización en aquellas dimensiones del intercambio comercial en donde esto conlleve ganancia social? Estas preguntas se relacionan con importantes desafíos de desarrollo económico (e. g., formalización de mercados) y de política pública (desafíos de fiscalización, políticas tributarias y arancelarias). La escasez de conocimiento público sobre estos temas, sobre todo en lo que respecta a sectores productivos como el analizado en este trabajo, señaliza áreas de debate con evidente necesidad de mayor investigación y análisis.

${ }^{38}$ Adicionalmente, la Dirección de Obras Públicas destina otros US\$ 7,5 mills./año al financiamiento de infraestructura de apoyo a la actividad pesquera del sector artesanal. Agradecemos a Andrés González (Subpesca) por proveernos esta información. 


\section{REFERENCIAS}

Acheson, J. M. (1988): The Lobster Gangs of Maine. New Hampshire: University Press of New England.

Agüero, M. (2001): "Seguimiento y Evaluación Social y Económica de las Áreas de Manejo y Explotación de los Recursos Bentónicos”. En Informe Final de Proyecto sobre Áreas de Manejo y Explotación de Recursos Bentónicos. Sercotec/Subpesca, diciembre.

Anderson, E. (1994): "Crop Sharing in the Fishery and Industry Equilibrium: Comment”. En Marine Resource Economics, Vol. 9: 67-72.

Anderson, J. L. (2003): The International Seafood Trade. Abington, Cambridge, U.K.

Arnason, R. (1995): The Icelandic Fisheries. Evolution and Management of a Fishing Industry. U.K: Fishing News Books, Woodhead Publishing Limited.

Bardhan, P. (1989): The Economics Theory of Agrarian Institutions. Oxford: Clarendon Press.

Barkema, A., M. Drabenstott y N. Novack (2001): “The New U.S. Meat Industry”. En Federal Reserve Bank of Kansas City: Economic Review, Segundo trimestre, www.kc.frb.org/

Basu, K. (1997): Analytical Development Economics. Cambridge, Massachusetts: The MIT Press.

Berkes, F. (ed.) (1989): Common Property Resources: Ecology and Community-Based Sustainable Development. London: Belhaven Press.

Braverman, A. y J. Stiglitz (1982): "Sharecropping and the Interlinking of Agrarian Markets”. En American Economic Review, 72 (4), pp. 695-715.

Castilla, J. C. (1994): "The Chilean Small-Scale Benthic Shellfisheries and the Institutionalization of New Management Practices”. En Ecology International Bulletin, 21, pp. 21-63.

Clark, C. y G. R. Munro (1980): "Fisheries and the Processing Sector: Some Implications for Management Policy”. En Bell Journal of Economics, 11 (2), pp. 603-616.

Cordell, J. C. y M. A. McKean (1992): “Sea Tenure in Bahia, Brazil”. En D. Bromley (ed.), Making the Commons Work: Theory, Practice, and Policy. San Francisco: Institute of Contemporary Studies Press.

Crutchfield, J. A. y G. Pontecorvo (1969): The Pacific Salmon Fishery: a Study of Irrational Conservation. Baltimore: John Hopkins University Press.

De Soto, H. (1987): El Otro Sendero. La Revolución Informal. Buenos Aires: Editorial Sudamericana.

Doeringer, P. B. y D. G. Terkla (1995): Troubled Waters: Economic Structure, Regulatory Reform and Fisheries Trade. Toronto: University of Toronto Press.

Gallick, E. (1984): "Exclusive Dealing and Vertical Integration: The Efficiency of Contracts in the Tuna Industry”. En FTC, Bureau of Economics, Staff Report, agosto. (Reimpreso en S. Masten, ed.: Case Studies in Contracting and Organization. New York: Oxford University Press, 1996.)

Geirsson, M. y T. Trondsen (1991): "Frozen Cod Products in the US market”. En W. Schrank y N. Roy (eds.), Econometric Modelling of the World Trade in Groundfish. Canada: Kluwer Academic Publishers. 
Glover, D. J. y K. C. Kusterer (1990): Small Farmers, Big Business: Contract Farming and Rural Development. London: Macmillan.

Gonzalez, E. (1996): “Territorial Use Rights in Chilean Fisheries”. En Marine Resource Economics, 11: 211-218.

Howard, W. H., E. Van Duren y H. McKay (1996): "Establishing Vertical Alliances: Case Studies and Heuristics”. En D. Martimort (ed.), Agricultural Markets: Mechanisms, Failures and Regulations. Elsevier Publishers.

IFOP (2003): “Investigación Situación Pesquería Demersal Austral 2002”. En IFOP, Informe Final: Programa de Seguimiento del Estado de Situación de las Principales Pesquerías Nacionales. Valparaíso, mayo.

Kenney, R. y B. Klein (1983): “The Economics of Block Booking”. En Journal of Law and Economics, Vol. 26, pp. 497-540, octubre.

Korovkin, T. (1992): "Peasants, Grapes and Corporations: The Growth of Contract Farming in a Chilean Community”. En The Journal of Peasant Studies, 19 (2): 228-254.

Koss, P. (1999): "Self-Enforcing Transactions: Reciprocal Exposure in Fisheries”. En Journal of Law, Economics and Organization, 15 (3): 737-749.

Little, P. D. y M. L. Watt (eds.) (1994): Living under Contract: Contract Farming and Agrarian Transformation in Sub-Saharian Africa. The University of Wisconsin Press.

Martinez, S. (1999): "Vertical Coordination in the Pork and Broiler Industries: Implications for Pork and Chicken Products”. En Food and Rural Economics Division, Economic Research Service, U.S. Department of Agriculture, Agricultural Economic Report, № 777.

Martinez, S. (2002): “A Comparison of Vertical Coordination in the U.S. Poultry, Egg and Pork Industries". En Food and Rural Economics Division, Economic Research Service, U.S. Department of Agriculture, Agriculture Information Bulletin, $\mathrm{N}^{\circ} 707$, mayo.

Masten, S. E. (ed.) (1996): Case Studies in Contracting and Organization. New York: Oxford University Press.

Matamala, M. (2004): "Sistematización y Difusión de la Cadena de Comercialización de Merluza del Sur Procedente de la X Región Hacia el Mercado Español”. Informe Técnico para Sercotec, X Región; diciembre, p. 25.

McCay, B. (1980): “A Fishermen’s Cooperative, Limited: Indigenous Resource Management in a Complex Society”. En Anthropological Quarterly, 53 (1), pp. 29-38.

Munro, G. R. (1982): "Bilateral Monopoly in Fisheries and Optimal Management Policy”. En L. Mirman y D. Spulber (eds.), Essays in the Economics of Renewable Resources. North Holland, Amsterdam.

Orensanz, J. M. (2001): “Derechos de Uso Territorial como Instrumento de Manejo de Pesquerías: Antecedentes”. Mimeo presentado en el “Taller de Áreas de Manejo” organizado por Subpesca, Puerto Montt, agosto.

Ostrom, E. (1990): Governing the Commons. The Evolution of Institutions for Collective Action. Cambridge, Massachusetts: Cambridge University Press.

Ostrom, E., R. Gardner y J. Walker (1994): Rules, Games \& Common-pool Resources. University of Michigan Press. 
Palma, M. y C. Chávez (2004): “Normas y Cumplimiento en Áreas de Manejo de Recursos Bentónicos: Estudio de Casos en la Región del Bío Bío”. Mimeo, Depto. de Economía, Universidad de Concepción.

Platteau, J.-Ph. y J. Nugent (1992): "Share Contracts and their Rationale: Lessons from Marine Fishing”. En Journal of Development Studies, Vol. 28 (3): 386422.

Peña-Torres, J. (1997): "The Political Economy of Fishing Regulation: The Case of Chile”. En Marine Resource Economics, 12 (4), pp. 239-248.

Peña-Torres, J. (2002): "Debates sobre Cuotas Individuales Transferibles: ¿Privatizando el Mar? ¿Subsidios? o ¿Muerte Anunciada de la Pesca Extractiva en Chile?”. En Estudios Públicos 86, pp. 183-222.

Peña-Torres, J. y E. Vespa (2005): "Pesquería del Bacalao de Profundidad: Subastas de Cuotas de Captura y Pesca Internacional Ilegal”. Mimeo, Depto. de Economía, Universidad Alberto Hurtado.

Pirrong, S. (1993): "Contracting Practices in Bulk Shipping Markets: a Transaction Cost Explanation”. En Journal of Law \& Economics, Vol. 36, octubre. (Reimpreso en S. Masten, ed.): Case Studies in Contracting and Organization. Nueva York: Oxford University Press, 1996.)

Ray, D. (1998): Development Economics. Princeton University Press.

Revista Mar (1999): “El Fraude en Pescados Congelados y Envasados, Más Dificil”, No377, pp. 24-27, noviembre, España.

Rivas, D. (2000): "Veda Extractiva para el Recurso Loco en las Regiones I a XI". Informe Técnico $\mathrm{N}^{\circ}$ 06, Subsecretaría de Pesca, p. 30, enero; Valparaíso.

Ruddle, K. (1988): "Social Principles Underlying Traditional Inshore Fishery Management Systems in the Pacific Basin”. En Marine Resource Economics, 5, pp. 351-363.

Schworm, W. E. (1983): "Monopsonistic Control of a Common Property Renewable Resource”. En Canadian Journal of Economics, 16, pp 275-287.

Scott, C. D. (1984): "Transnational Corporations and Asymmetries in the Latin American Food System”. En Bulletin of Latin America Research, 3 (1), pp. 63-80.

Seabright, P. (1993): "Managing Local Commons: Theoretical Issues in Incentive Design”. En Journal of Economic Perspectives, 7 (4).

Sernapesca (2001): "Elementos al Ordenamiento Pesquero de la Pesquería de Merluza del Sur, Aportado por los Pescadores Artesanales de la X y XI Regiones”. Informe Técnico, Dirección Zonal regiones X y XI, Pto. Montt, Chile.

Sernapesca (2001, 2002): Anuarios Estadísticos de Pesca. Valparaíso.

Sethi, R. y E. Somanathan (1996): "The Evolution of Social Norms in Common Property Resource Use”. En American Economic Review, 86 (4), pp. 766-788.

Stollery, K. (1987): "Monopsony Processing in an Open Access Fishery”. En Marine Resource Economics, 3 (4), pp. 331-351.

Subpesca (1996): “Chile Azul. Principales Recursos Pesqueros”. Diciembre.

Subpesca (2002): “Antecedentes Económicos y de Mercado de la Pesquería de Merluza del Sur”. En Informe DAS Nº4, noviembre.

Subpesca (2003): “Ficha Técnica No 4: Merluza del Sur”. Valparaíso, agosto.

Subpesca (2004): "Ficha pesquera No 5, Merluza del Sur”. Valparaíso, noviembre.

Subpesca (2004): “Informe Sectorial Pesquero 2003”. Valparaíso. www.subpesca.cl 
Sutinen, J. G. (1979): “Fishermen's Remuneration Systems and Implications for Fisheries Development”. En Scotttish Journal of Political Econom, Vol. 26 (2): 147-162.

Thomas, J. (1999): “Quantifying the Black Economy: 'Measurement Without Theory' Yet Again?”. En Economic Journal, 109, Nº 465: 381-389. 